\title{
El pluralismo jurídico y los derechos a la Pachamama
}

\author{
Legal Pluralism and the Rights to Pachamama
}

\author{
Alcides Antúnez Sánchez ${ }^{1} \bowtie$, Eduardo Díaz Ocampo ${ }^{2}$ \\ ${ }^{1}$ Magíster en Asesoría Jurídica, licenciado en Ciencias Penales, licenciado en Derecho. Profesor auxiliar \\ Derecho Ambiental e Internacional, Departamento de Derecho, Facultad de Ciencias Económicas y Sociales, \\ Universidad de Granma, República de Cuba. \\ ${ }^{2}$ Doctor en Jurisprudencia, magíster en Desarrollo Curricular, licenciado en Ciencias de la Educación, \\ licenciado en Ciencias Económicas, Políticas y Sociales. Abogado de los Tribunales de la República \\ del Ecuador, profesor de Derecho Laboral y Derecho Constitucional, rector de la Universidad Técnica \\ Estatal de Quevedo, Ecuador.
}

Correo electrónico: antunez1963@gmail.com y edu66diaz@hotmail.com

Recibido: 19 de noviembre del 2017 Aprobado: 7 de enero del $2018 \quad$ Disponible en línea: 1 de abril del 2018

Cómo citar este artículo: Alcides Antúnez-Sánchez y Eduardo Díaz-Ocampo. El pluralismo jurídico y los derechos a la Pachamama. DIXI 27. Abril 2018. doi: https://doi.org/10.16925/di.v20i27.2398

\section{Resumen}

Objetivo: demostrar el reconocimiento constitucional que se le ha dado a la naturaleza en la nación ecuatoriana, lo que le ha permitido ser sujeto de derechos como novedad jurídica en construcción y evolución en el siglo xxl, así como de su desarrollo normativo dentro del derecho positivo y en las políticas públicas.

Metodología: para ello fueron utilizados el método histórico-jurídico, el de análisis-síntesis y el de inducción-deducción.

Hallazgos: a partir de las últimas décadas del siglo xx, el pluralismo jurídico ha cobrado relevancia por su incidencia en el escenario social. La Filosofía del Derecho y la Sociología, aunque con orientaciones y posturas diversas, se ocupan de la definición de nuevos constructos teóricos requeridos para abordar la esencia del pluralismo jurídico en el contexto actual, reevaluándolo y brindándole nuevas vertientes de análisis.

Conclusiones: el Estado ecuatoriano garantiza a los pueblos indígenas la conservación y el desarrollo de sus formas tradicionales de convivencia y organización social, pues constituyen una expresión de la interculturalidad. Esto ha tenido una incidencia positiva en la protección constitucional a la naturaleza y en su desarrollo normativo a partir de los textos constitucionales.

Palabras clave: Abya Yala, buen vivir, derechos de la naturaleza, pluralismo jurídico. 


\title{
Legal Pluralism and the Rights to Pachamama
}

\begin{abstract}
Aim: To show the constitutional recognition that nature has gained in the Ecuadorian nation, which has allowed it to be subject of rights and duties as a legal novelty in the construction and evolution of the $21^{\text {st }}$ century, as well as its regulatory development within positive law and public policies.

Methods: For this, the historical-legal, analysis-synthesis and induction-deduction methods were employed.

Findings: From the last decades of the $20^{\text {th }}$ century, legal pluralism has become relevant due to its impact on the social scene. While having various orientations and positions, Philosophy of Law and Sociology deal with the definition of new theoretical constructs required to address the essence of legal pluralism in the current context, reevaluating it and providing new aspects of analysis.

Conclusions: The Ecuadorian State guarantees the conservation and development of the indigenous peoples' traditional forms of coexistence and social organization since they constitute an expression of interculturality. This has had a positive effect on the constitutional protection of nature and its regulatory development based on constitutional texts.
\end{abstract}

Keywords: Abya Yala, good living, rights of nature, legal pluralism.

\section{O pluralismo jurídico e os direitos da Pachamama}

\section{Resumo}

Objetivo: demonstrar o reconhecimento constitucional que foi dado à natureza na nação equatoriana, o qual Ihe permitiu ser sujeito de direitos como novidade legal em construção e evolução no século XXI, assim como o seu desenvolvimento normativo no direito positivo e nas políticas públicas.

Metodologia: os métodos histórico-jurídico, análise-síntese e indução-dedução foram utilizados para esse fim.

Resultados: das últimas décadas do século xx, o pluralismo jurídico tornou-se relevante devido ao seu impacto no cenário social. A Filosofia do Direito e a Sociologia, embora com orientações e posições diferentes, determinam novos construtos teóricos necessários para abordar a essência do pluralismo jurídico no contexto atual, reavaliando-0 e fornecendo assim novos aspectos de análise.

Conclusões: 0 Estado equatoriano garante aos povos indígenas a conservação e o desenvolvimento de suas formas tradicionais de convivência e organização social, visto que constituem uma expressão de interculturalidade. Este assunto teve um impacto positivo na proteção constitucional da natureza e no seu desenvolvimento normativo com base nos textos constitucionais.

Palavras-chave: Abya Yala, bem viver, direitos da natureza, pluralismo jurídico. 


\section{EXORDIO}

En el neoconstitucionalismo latinoamericano, la nación del Ecuador se ubica en la lista histórica de países pioneros en el ejercicio del constitucionalismo ambiental, pues se precia de haber planteado la inédita problemática entre los nuevos principios constitucionales ambientales y aquellos principios tradicionales del Derecho constitucional. Ecuador es pionero en incorporar a la "Naturaleza" en la Carta Política como sujeto de Derecho en sí mismo, así como los derechos que, como sujeto, le son propios. Para ello, dentro del pluralismo jurídico se reconocen nuevas instituciones jurídicas que dan protección a la naturaleza, en la cultura y la idiosincrasia ecuatorianas, en relación con las comunidades indígenas como parte del acervo cultural. Como hecho jurídico novedoso, al ser una visión ajena a la tradición jurídica occidental -no solo dentro del ordenamiento jurídico de esta nación, sino también en el contexto de América Latina-, es que se le precia como una novedosa institución jurídica.

Los retos intelectuales referentes a la teoría política que plantean los nuevos retos del texto constitucional son paradigmáticos; por ello son mayores en la materia jurídica ambiental. En cuanto a la inclusión de una serie de principios procedentes del Derecho consuetudinario de los pueblos originarios como nuevos valores del Estado, se presupone que la sociedad deberá aceptarlos y reconocer su vinculación jurídica, pero para su logro deberá incrementarse la cultura jurídica en los ciudadanos y en los operadores del Derecho, pues es un constructo novedoso y en desarrollo dentro del pluralismo jurídico. Esto llevará y obligará a su desarrollo en el ordenamiento jurídico dentro del Derecho ecuatoriano, con una orientación dirigida a la sistematización normativa interna e internacional del Derecho ambiental, a la creación de los correspondientes órganos de tutela ambiental y a la definición de los procedimientos que hagan posible y faciliten la exigibilidad del respeto a tales derechos en el cuerpo jurídico que lo regule, como paradigma de la Administración Pública.

Son estos elementos los que se tienen en cuenta, toda vez que el medio ambiente no está desligado de la economía como parte del nuevo esquema de desarrollo que se reconoce en esta Carta Magna. Por un lado, sirve de respuesta a una serie de demandas elevadas por la sociedad, y por otro, hace frente a una limitación de un desarrollo tecnológico incontrolable, en el que deben observarse los principios que aporta el
Derecho ambiental, como son el de precaución y el de prevención, entre otros. De aquí la necesidad de que los servidores públicos implementen de manera adecuada las herramientas de gestión y el control administrativo ambiental. Está claro que la constitucionalización de los derechos a la naturaleza se ha convertido en una necesidad de legitimidad de los Estados y de los modelos políticos y económicos que se establecen. Empero, hay que señalar que fue el Derecho internacional el que primero se preocupó por esta problemática a escala global ${ }^{1}$.

\section{El PLURALISMO JURÍDico.}

\section{PRINCIPALES CRITERIOS DOCTRINALES}

La reflexión sobre el pluralismo jurídico constituye uno de los debates más importantes de la ciencia jurídica contemporánea. Por un lado, están los teóricos que consideran al Derecho estatal como la única propuesta regulativa de la modernidad. Se basan en esa teoría positivista tradicional que expone las leyes como la principal fuente de Derecho. Por otro lado, se encuentran los que consideran al Derecho estatal como una fuente más de regulación sobre los conflictos sociales. La aceptación de que pueden existir diversos órdenes o sistemas jurídicos en un mismo territorio y para los mismos ciudadanos lleva a una imagen del fenómeno jurídico distinta a la tradicional; implica que el monismo jurídico se ha roto y que la juridicidad ha estallado, dando lugar a múltiples normatividades. Hecho que genera una imagen distinta del poder. Las categorías e instituciones jurídicas ideadas desde la concepción monista del Derecho, sobre la base del postulado Estado-Nación-Soberanía como expresión de cultura unidireccional, no están concebidas para explicar la vida empírica de sistemas normativos distintos al estatal, erigiéndose a partir de una cultura diferente. Sin embargo, las nociones de monismo, dualismo y pluralismo jurídico son propias del desarrollo de la filosofía jurídica del siglo $\mathrm{xx}$.

\footnotetext{
Véase Raúl De Almeida Amoy. Protección del Derecho del Medio Ambiente en el derecho interno e internacioNAL. Editorial Método. (2012). Págs. 13-58; José Juste Ruiz. La evolución del Derecho Internacional del Medio Ambiente. Autonomies: Revista Catalana de Dret Públic 15. 1992. Págs. 45-60; Vicente De Oliveira Mazzuoli. El Derecho Internacional del Medio Ambiente en la Convención Americana de Derechos Humanos. AnUario Mexicano de Derecho Internacional 13. 2013. Págs. 7-49.
} 
El movimiento del Derecho Libre contribuyó a consolidar en el siglo xx el paradigma del pluralismo jurídico, aportando sus principales fundamentos teóricos. Para los autores del referido movimiento, el pluralismo jurídico se entremezcla con la concepción sociológica de las fuentes del Derecho, que dichos autores propugnaron. Este paradigma implica la idea de que, junto al Derecho estatal, existen otros "Derechos" u otros sistemas jurídicos que coexisten con aquel, unas veces armónicamente y otras veces en conflicto, pero que, en cualquier caso, viven "con independencia del Derecho estatal"2.

El pluralismo jurídico, concebido como la coexistencia de diversos órdenes jurídicos en un espacio geopolítico, cobró auge a finales del siglo xIx y en la primera mitad del xx como una reacción ante el positivismo que emprendió la reducción del Derecho en el marco del proyecto moderno; pero solo en la década de los sesenta se convirtió en un tema de discusión central en la Antropología y la Sociología del Derecho. En la construcción de presupuestos de igualdad para generar diálogos interculturales, se aprecia los que en definitiva signan la comunicación entre culturas, incluso en el interior de cada una de estas en el escenario donde se desarrollan. Es la posibilidad de que en un mismo momento coexistan varios sistemas jurídicos, lo que supone un pluralismo de sistemas y no de pluralidad de mecanismos o de normas jurídicas.

El pluralismo jurídico se define como la coexistencia de varios sistemas jurídicos superpuestos en el mismo espacio geopolítico, en un mismo plano de igualdad, de respeto y de coordinación, que presenten un carácter socialmente vinculante, eficaces en el territorio donde rigen por la existencia de una pluralidad de entes creadores, productores y de solución de los conflictos que se susciten en cada territorio. En Antropología, desde 1978, han sido constantes los estudios sobre la discusión acerca de las características de la oposición entre pluralismo y monismo jurídico, basadas en la codificación de la ley estatal. Por otro lado, la crisis del Estado de Derecho y la aparición en los años noventa de la discusión jurídica

2 Véase André Jean Arnaud y María José Fariñas Dulce. Sistemas JURÍdicos. ElEMENTOS PARA UN ANÁLISIS SOCIOLÓGICO. Boletín Oficial del Estado. (2006). Pág. 90. de bienes básicos (agua, tierra, recursos...) han reavivado la polémica sobre el pluralismo jurídico ${ }^{3}$.

Por ello, reconstruir los orígenes del pluralismo jurídico es un tema complejo. Sin embargo, los autores paradigmáticos que lo han abordado como Ehrlich, Romano, Carbonnier, Arnaud y Bobbio permiten entender el nacimiento desde una visión pluralista del Derecho en sus estudios jurídicos. Esto pone de manifiesto el carácter polisémico del pluralismo jurídico. La idea que se defiende reside en la incapacidad de la ciencia jurídica tradicional para explicar los fenómenos jurídicos contemporáneos, pues considera que la realidad rebasa sus marcos explicativos, de ahí que el pluralismo jurídico -siguiendo la terminología de Kuhn- aparezca como una "anomalía" que pretende constituirse en un nuevo "paradigma" que desafía la limitación de las teorías jurídicas tradicionales ${ }^{4}$.

El primero de estos autores en hablar de un Derecho viviente y de la posibilidad de una pluralidad de sistemas jurídicos fue Ehrlich, quien refiere que el punto central del Derecho no se encuentra en la legislación, ni en la ciencia jurídica, ni en la jurisprudencia. Lo sitúa en la sociedad misma, puesto que el Derecho es un orden interno de las relaciones sociales, como las familias, las corporaciones, etc. ${ }^{5}$. Existe un Derecho viviente que puede ser conocido utilizando diferentes fuentes, en particular la observación directa de la vida social, las transformaciones, los hábitos y los usos de todos los grupos - no solamente de aquellos reconocidos jurídicamente, sino también de los grupos ignorados o despreciados por el Derecho e incluso condenados por el Derecho-.

\footnotetext{
Véase Pompeu Casanovas. Dimensiones del pluralismo JURÍDICO, en IX Congreso de Antropología FAAE, Universidad Autónoma de Barcelona, Madrid, 2002; Masaji Chiba. Una definizione operativa di cultura giuridica nella prospettiva occidentale e non occidentale. Sociologia del Diritto 3. 1999. Págs. 73-88; Leopold Pospisil y John Griffiths. What is Legal Pluralism? JournaL of Legal Pluralism 24. 1986. Págs. 1-55.

4 Para comprender la emergencia de unos paradigmas a partir de la crisis de otros, véase el planteamiento formulado por Kuhn, para quien un paradigma consiste en "[...] realizaciones científicas universalmente reconocidas que, durante cierto tiempo, proporcionan modelos de problemas y soluciones a una comunidad científica". Véase Thomas Kuhn. La estructura de las Revoluciones Científicas. Trad. Agustín Contín. Fondo de Cultura Económica. (2001). Pág. 13.

5 Véase Eugène Ehrlich. La norme juridique est une règle sociale parmi d'autres. Eds. Christophe Grzegorczyk, Françoise Michaut y Michel Troper. Le positivisme juridiQue. Editore LGDJ. (1993). Págs. 103-105; Eugène Ehrlich. La sociologia del diritto. Rivista Internazionale di Filosofia del Diritto 2. 1992. Págs. 102-107.
} 
Su naturaleza jurídica es un orden interno de relaciones sociales o, mejor, una organización de grupos sociales, es decir, un conjunto de reglas que determinan la posición y la función de los individuos miembros del grupo y más particularmente la condición de dominación o de subordinación de estos y las tareas asignadas en el seno del grupo.

En esta misma línea de ideas, Romano señala que la pluralidad de sistemas jurídicos resulta de la crisis de la hegemonía del Estado moderno, formado a partir de la eliminación y la absorción de los órdenes jurídicos superiores e inferiores y de la monopolización de la producción jurídica. Pero la vida social, más imperiosa y fuerte que el Derecho estatal, ha edificado, paralelamente y en ocasiones en oposición al Estado, una serie de órdenes parciales, en cuyo seno sus relaciones pueden extenderse en condiciones más convenientes. Se trata de sistemas que, precisamente porque no son reconocidos por el Estado, no están en la posibilidad de asegurarse una eficacia completa. El Derecho estatal, en la medida en que desconoce e ignora estos sistemas, termina por sufrir también un cierto grado de ineficacia ${ }^{6}$.

Por consiguiente, la existencia de diversos órdenes jurídicos nos remite a la sociedad medieval, donde la descentralización territorial y la diversidad de centros de poder configuraron en cada espacio social un amplio espectro de manifestaciones normativas concurrentes, con el conjunto de costumbres locales, foros municipales, estatutos de las corporaciones por oficio y dictámenes reales en el Derecho Canónico y en el Derecho Romano 7 . Esta diversidad de órdenes jurídicos se constata que fue causada por la debilidad, o apenas existencia, de un Estado capaz de producir una normatividad coercitiva. La naturaleza del referido fenómeno jurídico sufrió una radical transformación con el surgimiento y la consolidación de los Estados centralizados.

Se comprueba cómo, desde las últimas décadas del siglo xx, el pluralismo jurídico ha cobrado relevancia por su incidencia en el escenario social. Algunos autores vinculados a la tradición de la Filosofía del

\footnotetext{
6 Véase Santi Romano. L'ordenamento GIURIDICO. Editoria Sansoni. (1951). Págs. 13-27.

Véase Francisco Cuena Boy. Sistema jurídico y Derecho ROMANO. LA IDEA DE SISTEMA JURÍDICO Y SU PROYECCIÓN EN LA EXPERIENCIA JURÍDICA ROMANA. Universidad de Cantabria. (1998); Alfredo Di Pietro. La prudente tarea de interpretación en el Derecho Romano. Anuario de Filosofía Jurídica y Social 9. 1989; Sabino Ventura Silva. Derecho Romano. Editorial Porrúa. (1996).
}

Derecho y a la Sociología, aunque con orientaciones y posturas diversas entre sí, se ocupan de la definición de nuevos constructos teóricos, requeridos para abordar la esencia del pluralismo jurídico en el contexto actual, reevaluándolo y brindándole nuevas vertientes de análisis ${ }^{8}$.

En América Latina, reconocido o no, el pluralismo jurídico constituye una realidad social objetiva, fundada sobre la idea genérica de la coexistencia de más de un sistema jurídico en un espacio geopolítico, y polemiza con la concepción monista del Derecho, propio de un modelo agotado. Se aprecia su reconocimiento jurídico de forma expresa y tácita en Ecuador, dentro de su texto constitucional, como referente en la región de América Latina para las naciones que aún no lo han realizado en sus ordenamientos jurídicos. Son estos elementos los que permitirán demostrar cómo la naturaleza ha sido reconocida como sujeto dentro del texto constitucional en Ecuador, dada su importancia para proteger la biodiversidad en la región Amazónica como pulmón del globo terráqueo.

\subsection{El Pluralismo Jurídico en Clave Constitucional Ambiental}

Ya se reseñaba que la premisa central del pluralismo jurídico es que el Estado no es la única fuente de normas y prácticas legales, sino que coexiste con muchos otros espacios donde se generan normas y se ejerce control social. Un paneo de la geopolítica en América Latina permite conocer cómo desde la ancestralidad los pueblos originarios ya ponderaban a la naturaleza; ejemplo de ello es cuando los incas imponían penas severas a las personas que dañaran a las aves productoras de guano y establecían cuotas de uso de agua a los agricultores. Los mayas, por su parte, imponían ciclos de uso y descanso de la tierra, respetaban

8 Véase Henry Levy-Bruhl. Sociología DeL Derecho. Editorial Universitaria. (1964). Págs. 14-15; Jacques Vanderlinden. DiCTIONNAIRE ENCYCLOPÉDIQUE DE THÉORIE ET DE SOCIOLOGIE DU DROIT. LGDJ y Story-Scientia. (1988). Págs. 300-303; Jacques Vanderlinden. État et la régulation juridique des sociétés globales. Pour une problématique du pluralisme juridique. Sociologie ET SociétÉs 1. 1986. Págs. 11-32; Boaventura De Sousa Santos. O DISCURSO E O PODER: ENSAIO SOBRE A SOCIOLOGIA DA RETÓRICA JURÍdiCA. Fabris. (1988). Págs. 64-78; André Arnaud. LEgaL Culture And Everyday Life. Edition Oñati Proceedings. (1989). Págs. 129-136; Masaji Chiba. Legal Pluralism in Sri Lankan Society. Toward a General Theory of Non-Western Law. JourNAL OF LEGAL Pluralisim and Non-Official Law 31. 1989. Págs. 1-19; Pospisil y Griffiths, supra, 1986, nota 3, Pág. 15. 
lo que esta producía y rogaban perdón por el daño causado. Sin embargo, siguiendo la cronología histórico-política de estos procesos en Latinoamérica, la Constitución de México de 1917 tiene el mérito de ser la precursora de promover constitucionalmente el tema ambiental, dirigido a la protección de la propiedad privada?.

Por consiguiente, este legado de los pueblos originarios en la nación ecuatoriana está presente en el artículo 1: "El Ecuador es un Estado [...] constitucional de derechos y de justicia, social, democrático, soberano, independiente, unitario, intercultural, plurinacional y laico [...]". A tenor de que como Estado es firmante del Convenio 169 de la oit de 1989, de la Declaración de Principios de las Naciones Unidas sobre el Medio Ambiente y de la Declaración de las Naciones Unidas sobre los Derechos de los Pueblos Indígenas de 2007, entre otros instrumentos internacionales. Esto permite ponderar el giro que se le ha dado al constitucionalismo en Latinoamérica y en especial al Ecuador.

Cuando el Estado ecuatoriano reconoce y protege la existencia de los pueblos y las comunidades indígenas como pueblos originarios, les garantiza los derechos consagrados en la Constitución del 2008, reconociéndoles y respetándoles el derecho tradicional autóctono, lo cual es de suma importancia para la protección ambiental, toda vez que las circunstancias en que se presenta la relación de estos grupos con el medio ambiente están llenas de tradiciones, valores ancestrales y espiritualidad; cosa diferente a la relación que guardan los miembros del resto de la sociedad. Se valora que para poder desarrollar y aplicar el pluralismo jurídico en materia ambiental, hay que partir prácticamente desde el origen mismo, a fin de generar los derechos ambientales efectivos para todos los habitantes de una sociedad determinada y que sean respetadas las diferentes cosmovisiones representadas en el sumak kawsay. Para esto, hay que partir del concepto del derecho humano al medio ambiente, que permita el desarrollo de cuerpos jurídicos ambientales en el ordenamiento jurídico con

\footnotetext{
9 Véase Orlando Rey Santos. El desarrollo del CONSTitu CIONALISMO AMBIENTAL EN LATINOAMÉRICA. PNUMA-ONU. (2008). Págs. 23-38; Néstor Caferatta. Constitucionalismo E INSTituCIONALIDAD AMBIENTAL EN LATINOAMÉRICA. LA DEMOCRACIA PARTICIPATIVA EN LAS DECISIONES AMBIENTALES. Editorial IneSemarnat. (2004). Pág. 23.
}

la óptica de los pueblos originarios, lo cual es una novedad en desarrollo ${ }^{10}$.

\section{El PLURALISMO JURÍDICO EN ECUADOR. LOS DERECHOS OTORGADOS A LA PACHAMAMA EN CLAVE CONSTITUCIONAL AMBIENTAL}

Es un hecho jurídico que la Constitución del 2008 se precia de ser uno de los textos constitucionales de mayor extensión en el subcontinente latinoamericano, y como carta política, reconoció instituciones y derechos de su antecesora en 1998 presentando un desarrollo más detallado en la protección a la naturaleza como línea central del ensayo jurídico. Al ser la norma suprema dentro del ordenamiento jurídico ecuatoriano, sus disposiciones son de directa e inmediata aplicación. Su valor jurídico es prevalecer sobre cualquier otra disposición normativa dentro del ordenamiento jurídico ecuatoriano ${ }^{11}$.

Esta Constitución del 2008, de las veinte que le antecedieron en este tracto sociojurídico, aporta cambios fundamentales en la vida de los ecuatorianos y en la institucionalidad estatal con un nuevo modelo de desarrollo, con divergencias entre la jurisdicción indígena y la ordinaria, y con inclusión de un sistema económico solidario y del buen vivir (sumak kawsay); es todo un reto en construcción. Toma como base la planificación y la incorporación de la transparencia y la participación social como instrumentos de gestión de la economía, del desarrollo de la justicia constitucional y de las garantías, con la materialidad de los derechos y la transformación de la institucionalidad. Ello permitirá mejorar los mecanismos de democracia directa y de inclusión de la participación social como equilibrio y ejercicio de nuevas formas de representación, con la revolución ciudadana ${ }^{12}$.

10 Véase Miguel Berraondo López. Los DeReChos MEdiOAMBIENTALES DE LOS PUEBLOS INDÍGENAS: LA SITUACIÓN EN LA REGIÓN AMAZÓNICA. Editorial Abya-Yala. (2000).

11 Véase Constitución de la República del Ecuador 2008, Decreto Legislativo, Registro Oficial N. ${ }^{\circ} 449$, fecha 20 de octubre de 2008.

12 Véase Adriana Rodríguez Salazar. TeORÍA y PRÁCTICA DEL BUEN VIVIR: ORÍGENES, DEBATES CONCEPTUALES Y CONFLICTOS SOCIAlEs. El CASO DE EcuAdor. Tesis doctoral, Universidad del País Vasco, Facultad de Derecho. (2016); Patricio Carpio Benalcázar. El BUEN VIVIR MÁs ALLÁ DEL DESARROLLO: LA NUEVA PERSPECTIVA CONSTITUCIONAL EN EL ECUADOR. Editorial AbyaYala. (2009). Pág. 125 
Ahora, el mérito de acuñar el tema del constitucionalismo ambiental en Latinoamérica es de Brañes Ballesteros, quien lo establece para "designar al conjunto de ideas jurídicas que comenzaron a aparecer, a partir de 1992, en las constituciones políticas de América Latina, en consonancia con el espacio que comenzaban a ocupar, en todo el mundo, las ideas sobre la protección del medio ambiente y el desarrollo sostenible"13. En su postura, lo aborda como un fenómeno político-jurídico nuevo. Lo enmarca:

[...] se trata de lo que hemos llamado un 'enverdecimiento' (greening) de las constituciones políticas de la región, que paulatinamente se han ido ocupando más y más de establecer las bases para el desarrollo de una legislación ambiental moderna. A este "enverdecimiento" de nuestras constituciones no han sido ajenas, por cierto, las dos grandes Conferencias de las Naciones Unidas sobre Medio Ambiente (de 1972 y 1992)..$^{14}$

De manera que se aprecia cómo incide en los veinte países que componen América Latina la influencia que permeó para que renovaran instituciones dentro de los textos constitucionales, y por ende, para que hicieran cambios en sus constituciones. Se aprecia que entre 1972 y 1999, en dieciséis de estos países se dieron nuevas constituciones políticas que procuraron incorporar las demandas de la sociedad latinoamericana, lo que ahora se le conoce como "movimientos sociales". Ello dio lugar a que se introdujeran importantes disposiciones como "principios", referidas a la protección del medio ambiente y a la promoción de un modelo de desarrollo sostenible, lo que al final vino a crear la etapa de "enverdecimiento" de las constituciones.

El 80\% de los pueblos indígenas son agropecuarios y rurales en la región Andina, y tienen una alta dependencia de los recursos naturales. Los demás han desarrollado sistemas y redes de comercio, sistemas de emigración temporal, nacional y global, y artesanías de importancia para la actividad comercial. Por ello, en este texto constitucional se elimina la clasificación de derechos por generaciones, siendo todos los derechos reconocidos de forma inmediata.

13 Véase Raúl Brañes Ballesteros. Informe deL Derecho AMbiENTAL EN LATINOAMÉRICA, ANÁLISIS HISTÓRICO-DOCTRINAL y JuRídico desde el Derecho Ambiental. pnuma-onu. (2001). Págs. 9-114.

14 Véase Raúl Brañes Ballesteros. Manual de Derecho AmBiental mexicano. Fondo de Cultura Económica. (2000). Pág. 99.
De esta forma, la exigibilidad de los derechos es garantizada en la vía judicial. Ávila Santamaría ${ }^{15}$ pondera sobre el contenido de los derechos colectivos que las principales creaciones tienen que ver con la inclusión de nuevos derechos colectivos, como el derecho a no ser objeto de racismo ni discriminación (artículos 57.2, 57.3), a mantener sus sistemas jurídicos propios (artículo 57.10), a constituir y mantener sus propias organizaciones (artículo 57.15), a ser consultados antes de la adopción de medidas legislativas que puedan afectar a esos pueblos o colectivos (artículo 57.17), el derecho a la limitación de actividades militares en sus territorios (artículo 57.20), a que la diversidad cultural se refleje en la educación pública $\mathrm{y}$ en los medios de comunicación, a tener sus propios medios (artículo 57.21), y los derechos de los pueblos en aislamiento voluntario (artículo 57, inciso final).

Ávila Santamaría valora en sus estudios que la Constitución de Montecristi tiene influencias marcadas del sistema continental europeo de la posguerra y hasta del sistema constitucional norteamericano. Del primero tiene la idea de control de la constitucionalidad y la del Tribunal Constitucional; del segundo, el control difuso de constitucionalidad. Tiene algunas novedades que son propias de la región latinoamericana y otras que son propias de los movimientos y luchas sociales de los ecuatorianos y de los andinos, como son la Pachamama, el sumak kawsay, la plurinacionalidad, la democracia comunitaria, la justicia indígena y la interculturalidad como instituciones novedosas y algunas en construcción.

Por ello, para abordar el tema de los derechos reconocidos a la naturaleza como sujeto en el texto constitucional ecuatoriano, se necesita de un estudio desde el comienzo del pensamiento filosófico; allí encontramos que Sócrates, en el año 339 a.C., indicó que movido por su deseo de conocer las causas de todos los fenómenos, emprendió el estudio sobre las opiniones acerca de la naturaleza de los filósofos anteriores a su tiempo: Anaxágoras, Empédocles y Anaxímenes, con quienes discrepaba; ellos explicaban la naturaleza a través de fenómenos y acciones, mientras que él pensaba en la esencia de las cosas y

15 Véase Ramiro Ávila Santamaría. Los DERECHOS Y SUS GARANTíAs. Editorial CEDEC. (2012). Pág. 78; Ramiro Ávila Santamaría. Ecuador. Estado constitucional de derechos y justicia. Constitución del 2008 en el contexto andino. Análisis de la doctrina y el Derecho comparado. Serie Justicia y Sociedad 3. 2008. Págs. 19-38; Ramiro Ávila Santamaría. El NEOCONSTITUCIONALISMo TRANSFORMAdor: El Estado y el DeRecho en la Constitución DE 2008. Editorial Abya-Yala. (2011). Págs. 83-121. 
su finalidad, pues así se podía comprender por qué suceden, por qué es conveniente que sucedan y qué relación tienen con el fundamento divino de todo. Así las cosas, Sócrates plantea la relación de los problemas (filosóficos) de la Naturaleza con las ciencias que, por ese entonces, eran fáciles de imaginar y tenían muy poco desarrollo.

En este orden, se pondera que fue en Roma donde aparecieron los primeros vestigios del Derecho ambiental, puesto que en esta época se crearon normas expresas en cuanto a la propiedad y una vez promulgadas las XII Tablas, se le otorgó al "páter familias" la propiedad de la tierra. También, se prohibió la circulación de carruajes dentro de los barrios para evitar el ruido, la cual se ha llegado a considerar como la primera norma ambiental conocida. En este cuerpo jurídico de las XII Tablas (490 a.C.), se disponían medidas de sanidad ambiental al prohibir la incineración de cadáveres cerca de centros poblados ${ }^{16}$.

Platón, hace unos 2.300 años, recomendaba la necesidad de reforestar las colinas de Ática (Grecia) para regular las aguas y evitar la erosión, y señalaba cómo dichas colinas ya se veían como esqueletos blancos. En el Código de Hammurabi se establecía, entre otras cosas, que "si un señor, sin el consentimiento del propietario de un huerto ha cortado un árbol en el huerto de otro señor pesará para indemnizarle media mina de plata"17.

La Biblia establece un orden lógico (y verificable en términos generales por la ciencia) en que la creación fue concluida. En un principio era la oscuridad y el Todopoderoso exclamó "fiat lux" "hágase la luz", luego creó la tierra y las aguas, las plantas; luego vinieron los animales y solo al final llegó el ser humano. Se puede apreciar que el concepto jurídico de contaminación nace en el año 533 en el Digesto, y es confirmado por la Constitución Tanta de 533, la cual dispone que hay una violación a las buenas costumbres cuando alguien ensucia las aguas o cañerías contaminándolas (contaminaverit) con cieno, lodo o estiércol.

Aristóteles también expuso varios conceptos sobre la naturaleza. En su obra, refiere a las cosas que son por naturaleza y a las otras que son por otras causas:

16 La Ley de las XII Tablas (lex duodecim tabularum o duodecim tabularum leges), o Ley de Igualdad Romana, fue un texto legal que contenía normas para regular la convivencia del pueblo romano. También recibió el nombre de Ley Decenviral. Por su contenido se dice que pertenece más al Derecho privado que al Derecho público. 17 Véase Código de Hammurabi. Editorial Tecnos. (2008).
Por naturaleza, los animales y sus partes, las plantas y los cuerpos simples como la tierra, el fuego, el aire y el agua -pues decimos que estas y otras cosas semejantes son por naturaleza-. Todas estas cosas parecen diferenciarse de las que no están constituidas por naturaleza, porque cada una de ellas tiene en sí misma un principio de movimiento y de reposo, sea con respecto al lugar o al aumento o a la disminución o a la alteración. Por el contrario, una cama, una prenda de vestir o cualquier otra cosa de género semejante, en cuanto que las significamos en cada caso por su nombre y en tanto que son productos del arte, no tienen en sí mismas ninguna tendencia natural al cambio; pero en cuanto que, accidentalmente, están hechas de piedra o de tierra o de una mezcla de ellas, y solo bajo este respecto, la tienen. Porque la naturaleza es un principio y causa del movimiento o del reposo en la cosa a la que pertenece primariamente y por sí misma, no por accidente.

De Aquino (1225-1274) sostuvo que la naturaleza es el fruto de un plan divino a través de los modos de ser y obrar. Para este autor, la naturaleza es el principio dinámico intrínseco que determina el comportamiento ordenado de los seres naturales y en definitiva es una creación de Dios. Copérnico (14731543) consideró a la Tierra no como un elemento inmóvil, situado en el centro del universo, sino como un planeta que gira alrededor del Sol, situación que causó una gran conmoción en esa época. Francis Bacon (1561-1626) buscó una nueva ciencia que sirviera para dominar la Naturaleza, y sustituyó las formas que pretendían expresar la naturaleza de las cosas por leyes. Bacon abandonó el método de la deducción y se centró en la inducción con la idea de que hay que "partir de la observación para remontarse hasta las leyes mediante una inducción metódica”.

Descartes (1596-1650), Kepler (1571-1630) y Galileo (1571-1630) contribuyeron al estudio de la Naturaleza. Estos autores introdujeron, en su orden, el enfoque matemático, la formulación de las nuevas leyes referidas a las trayectorias elípticas de los planetas, y la afirmación de que:

[...] el objetivo de la ciencia es formular leyes científicas, que expresan relaciones constantes entre los fenómenos y se refieren a las dimensiones cuantitativas (las «afecciones», tales como el lugar, el movimiento, la figura, la magnitud, etc.); en cambio, la filosofía busca explicaciones últimas basadas en las dimensiones 
cualitativas. Por lo que, la ciencia renuncia al conocimiento de las esencias y al estudio del significado profundo de las cosas.

En este sentido, se dieron también los aportes de Newton (1642-1727), quien formuló las tres leyes fundamentales del movimiento y, la más importante, la ley de la gravedad. Lo anterior cambia con Kant (1724-1804), que consideró válidos los conceptos de la Física de Newton, señalando que los conceptos científicos y, por lo tanto, los conceptos sobre la Naturaleza pertenecen al sujeto y dependen entonces de la manera individual de representarlos.

La posición de la Filosofía se esforzó tenazmente para explicar el mundo partiendo del mundo mismo. Holbach (1723-1789), en su obra Sistema de la naturaleza, alertaba: "El hombre ha sido la obra de la naturaleza, no existe más que en ella y es regido por sus leyes [...] Para un ser creado por la naturaleza y sometido a ella, nada existe fuera del conjunto o todo, del que forma parte, y que recibe toda especie de influencias". En esta misma línea de ideas analizadas, Hegel (17701831) publica en 1817 la Enciclopedia de las Ciencias Filosóficas e indica: "En la naturaleza, tanto como en el espíritu, lo que encontramos es la idea; pero en la naturaleza la idea reviste la forma de una existencia exterior, mientras que en el espíritu es la idea que existe en sí y para sí".

Ahora que acontece desde la ciencia del Derecho el análisis de los derechos reconocidos a la naturaleza como sujeto en el texto constitucional ecuatoriano, se parte de su definición como el orden que integra el contenido de códigos, leyes, reglamentos o costumbres como preceptos obligatorios reguladores o supletorios establecidos por el poder público o por el pueblo mismo a través de la práctica general reiterada o de la tradición usual. Esto configura el Derecho objetivo. El Derecho, al ser el reflejo del desarrollo de la sociedad, inicia desde la actividad del comercio y la formación de pequeñas asociaciones, hasta los tratados de cooperación internacional y la misma globalización. Él no ha generado el desarrollo, pero sí lo ha facilitado contribuyendo a la prevención y resolución de conflictos en muchas de las relaciones humanas. Las fuentes del Derecho constituyen el principio, fundamento $\mathrm{u}$ origen de las normas jurídicas, y en especial del Derecho positivo en determinada nación y época. Las fuentes del Derecho constituyen las costumbres, las leyes, la doctrina y la jurisprudencia en el caso el Derecho consuetudinario.
Ahora bien, la relación del hombre con la naturaleza en el siglo xxi no es adecuada. El mundo vive una crisis ambiental que se traduce en el deterioro de la calidad del aire, de los suelos y del agua, que afecta directamente a la biodiversidad y por lo tanto a la vida de los habitantes de este planeta. La civilización humana se enfrenta hoy a una crisis global y compleja que tiene al mundo de alguna manera desorientado y alerta. El tema es más profundo de lo que parece, estamos frente a una crisis ecológica y humanitaria. En una obligada mirada histórica a la dimensión social del medio ambiente, se parte de un término que se considera que está vinculado con lo ambiental y lo social, y que de alguna manera introduce desde una posición general al tema en cuestión; sería la supracuestión o el supratema: el bienestar humano. Probablemente, la preocupación más general de las personas es por su bienestar. Al margen de su contenido relativo o temporal y de su dudosa dualidad objetivo-subjetiva, el bienestar se limita hoy para algunos grupos poblacionales a la satisfacción de las necesidades más elementales de subsistencia, mientras que para otros representa la satisfacción de las necesidades y aspiraciones más elevadas de autorrealización.

No es un secreto que la región de América Latina es la porción más húmeda del planeta, aloja la mayor masa forestal y encierra la mayor diversidad biológica de la Tierra. En ella, habitan más de 400 grupos étnicos de los pobladores originarios, distribuidos en el vasto continente, con un alto crecimiento demográfico. La explotación indiscriminada de los recursos naturales, sin analizar ni tener en cuenta sus consecuencias negativas, ha causado un alarmante deterioro ecológico al planeta Tierra. La deforestación a manos de las transnacionales madereras y la extracción de hidrocarburos son dos ejemplos de agresión a la Madre Tierra.

En Ecuador, se aprecia que los problemas ambientales están vinculados a la contaminación proveniente del uso de vehículos en las ciudades de mayores dimensiones geográficas y poblacionales en relación con los derechos urbanísticos, como son Quito, Guayaquil y Cuenca, junto a la utilización de combustibles minerales para la producción de energía térmica. Los suelos son afectados por el avance de la frontera agrícola, por la desertificación y por los contaminantes que provienen de las aguas de riego, de la industria y de los desechos domésticos.

Hay otros inconvenientes que afectan al medio ambiente: la pérdida de la masa de bosques tropicales 
y páramos; la extinción progresiva de la flora y la fauna autóctonas; el calentamiento de la atmósfera; la erosión y la deforestación; la creciente contaminación del agua, el aire y el suelo; el tráfico de especies silvestres; la invasión de parques y reservas naturales; los problemas energéticos; el deterioro de las condiciones ambientales urbanas; y los riesgos, desastres y emergencias naturales y ambientales. Por ende, lo que sucede en el Ecuador no es un problema aislado. Con más o menos variaciones, los mismos problemas se presentan en todas las regiones del planeta, y de no resolverse, podríamos dejar de existir.

Siguiendo esta línea de análisis de los problemas ambientales, los derechos reconocidos a la naturaleza como sujeto han sido el resultado de las luchas de los pueblos, principalmente la lucha de los indígenas originarios emprendida en los últimos tiempos en la nación del Ecuador. Después de los muchos años que sucedieron a la conquista española y del dominio de las clases oligárquicas locales en el deterioro de las condiciones ambientales, se dio lugar a la formación de movimientos sociales que empezaron a presentarse en un escenario en donde nunca habían estado como actores sociales.

En los años noventa, ligado a los quinientos años de la llegada de Colón a América, se inició el movimiento indígena como sujeto político, liderado por la Confederación de Nacionalidades Indígenas del Ecuador (Conaie), creada en 1986. La Conaie se manifestó mediante la toma simbólica de la iglesia de Santo Domingo, en Quito. En esta ocasión, los líderes de los pueblos indígenas enviaron al presidente de la República su petición en relación con: el derecho de los indígenas a la tierra, la crítica al modelo agroexportador, el no pago a la deuda externa, la desigualdad en el trato a los sectores productivos y a las comunidades indígenas, y la preocupación por la contaminación causada por la explotación del petróleo en la Amazonia ecuatoriana por empresas transnacionales ${ }^{18}$.

Los movimientos sociales de los indígenas ecuatorianos consiguieron entonces una serie de reconocimientos: la declaración del país como un Estado plurinacional, la legalización de sus territorios a favor de los pueblos indígenas, la solución de algunos litigios en materia de aguas, el reconocimiento de la

18 Véase Jorge Salvador Lara. BREve historia CONTEMPoRÁNEA DEL ECUADOR. Editorial Fondo de Cultura Económica. (2010); Enrique Ayala Mora. Resumen de historia DEL EcuAdor. Editorial Corporación Nacional. (2008). Pág. 19. medicina tradicional y recursos para la educación bilingüe. Estas primeras reacciones indígenas no solo consiguieron lo que reclamaron como derechos, sino que además, haciendo acto de presencia en la política nacional, tuvieron el reconocimiento expreso y tácito en la Carta Magna. Desde entonces, los indígenas ecuatorianos fueron reconocidos como nacionalidades dentro de la nación ecuatoriana ${ }^{19}$. Esto demuestra que la lucha de los indígenas por el agua, por su cultura, por sus costumbres, en contra de la explotación indiscriminada de los recursos naturales, se ha convertido su razón de ser; los cambios que se han ido sucediendo en estos tiempos, sin lugar a dudas, han sido el producto de esa semilla que sigue en desarrollo.

Por consiguiente, en el análisis de cómo se ha protegido a la Pachamama en las Cartas Magnas de la República de Ecuador se aprecia que desde la Constitución de 1979, reformada en 1983, se le ha dado tratamiento; por ejemplo en el artículo 19: "El derecho a vivir en un medio ambiente libre de contaminación", como derecho que el Estado garantiza "sin perjuicio de otros derechos necesarios para el pleno desenvolvimiento moral y material que se deriva de la naturaleza de la persona". El artículo se completaba estableciendo: "Es deber del Estado velar por que este derecho no sea afectado y tutelar la preservación de la naturaleza. La Ley establecerá las restricciones al ejercicio de determinados derechos o libertades para proteger el medio ambiente".

La Constitución de 1984 introduce "el derecho a vivir en un ambiente libre de contaminación y la obligación del Estado a tutelar la preservación de la naturaleza”. Ya en la Constitución de 1998 se reconoce el principio de precaución y el derecho a que cualquier persona interponga acciones por la protección del medio ambiente. También en este cuerpo jurídico se declaró al desarrollo sustentable como objetivo permanente de la economía nacional, conociéndose como desarrollo sostenible, en sus articulados 23.6, $86,87,88,89,90,91$.

19 Constitución de la República del Ecuador 2008, supra, nota 11. El artículo 1 establece: "El Ecuador es un Estado [...] constitucional de derechos y de justicia, social, democrático, soberano, independiente, unitario, intercultural, plurinacional y laico [...]". Pone al Estado como garante de los derechos constitucionales a través de la preeminencia del análisis jurídico de los conflictos individuales y sociales; materializa la pluralidad como una puesta en igualdad de condiciones a los diversos sistemas jurídicos existentes en una sociedad plurinacional, se está inmerso en un proceso de construcción institucional, donde el sector judicial evoluciona hacia un modelo democrático, técnico y participativo. 
Se aprecia que estos dos textos jurídicos constituyeron el germen de los derechos concedidos a la naturaleza en la Constitución del 2008, la cual los sustituye en este análisis. Ello se dio con el tránsito del constitucionalismo neoliberal al constitucionalismo posmoderno; por ende, se transita de la concepción antroprocentrista a la biocentrista ${ }^{20}$. Como paradoja, mientras que en el mundo la naturaleza fue considerada como objeto, la nación ecuatoriana la reconocía como sujeto de derechos, todo un paradigma en materia constitucional ambiental dentro de la ciencia del Derecho.

Las pretensiones en este texto supremo fueron dirigidas a que la naturaleza tendría el derecho fundamental a la existencia; a mantener sus ciclos evolutivos; al reconocimiento de los derechos a la reparación integral, más allá de aquellos que afectan a una comunidad y persona, cuando esta haya sido degradada; o el derecho a las restricciones de actividades, tecnologías o políticas cuando se amenace la integridad del ecosistema; a que la naturaleza debería tener la titularidad, esto es, la condición de ser sujeto de derechos propios; a que la naturaleza debería tener la tutela, una institución jurídica creada para el ejercicio de los derechos de quienes no pueden exigirlos por sí mismos. Con la articulación de un movimiento de afectados por la industria petrolera en los países amazónicos, señalan como derechos de la naturaleza los siguientes: derecho a tener derechos propios; derecho a existir y perdurar, a florecer en el tiempo, a mantener sus ciclos vitales y evolutivos. A la naturaleza no se le pueden mezquinar sus derechos.

A su vez, tiene el derecho a tener guardianes: los pueblos indígenas son y han sido los custodios de la naturaleza. Han conservado y enriquecido la biodiversidad. Conservan un conocimiento profundo sobre los rituales sagrados de la vida. Tiene el derecho a tener defensores, quienes defienden a la naturaleza de las agresiones de las empresas o de los Estados;

\footnotetext{
20 Véase Constitución de la República del Ecuador 2008, Registro Oficial N. 1 del 11 de agosto de 1998; Silvia Jaquenod De Zsogon. El Derecho Ambiental y sus Principios Rectores. Editorial Dykinson. (1991). Pág. 372; Demetrio Loperena Rota. Los principios del Derecho Ambiental. Editorial Civitas. (1998). Pág. 87; Ramón Martín Mateo. Tratado de Derecho Ambiental. Editorial Trivium. (1998); José Esteve Pardo. Principio de precaución. El derecho ante la incerteza científica. Revista JURÍDICA DE Catalunya 3. 2003. Págs. 689-700; Dionisio Fernández De Gatta Sánchez. Principios del Derecho Ambiental, la responsabilidad social corporativa en materia ambiental. BOLETín ECONÓMICO ICE 2824. 2004; Néstor Caferrata. Teoría de los principios del Derecho Ambiental. Revista Abeledo Perrot. 2009.
}

no son criminales que afectan la propiedad o el desarrollo, son defensores de derechos fundamentales cuyo papel debe ser reconocido y estimulado, nunca reprimido.

Tiene el derecho a la reparación: más allá de la sustitución o limpieza de aquellas condiciones que afectan a las comunidades humanas. La naturaleza debe ser reparada, debe recuperarse su estructura y lograr que los ecosistemas puedan funcionar y mantener las condiciones de vida de todas las especies. Todos los miembros de la comunidad de la Tierra deben ser protegidos. Incluyendo todos los humanos, todos tienen derecho al sustento, a la protección, al respeto.

En vista de lo anterior, la protección a la naturaleza en el Derecho ambiental ecuatoriano tiene un desarrollo en el Derecho sustantivo a partir del siglo $\mathrm{xx}$, esto puede ser constatado en su ordenamiento jurídico. Ahora bien, es un hecho que este desarrollo ha sido continuado después del reconocimiento expreso y tácito de los derechos indígenas y del pluralismo jurídico, el cual ha tenido un desarrollo dentro de las políticas públicas en esta nación a través de la Estrategia Ambiental para el Desarrollo Sustentable (2000) y de la Política y Estrategia Nacional de Biodiversidad (2002). Se puede apreciar en la contextualización de estas políticas públicas con la creación de áreas protegidas en los parques nacionales Yasuní, Sumaco y Galápagos, que son parte del manejo de paisajes con categorías de Reservas de la Biosfera, y con los proyectos de corredores ecológicos y manejo de la conservación de ecosistemas comunes en Ecuador, en relación con el texto constitucional.

El sumak kawsay, dentro de la Pachamama como novedad jurídica, en su traducción literal del kichwa significa "buena vida" o "bien vivir". Este concepto proviene y se sintoniza con las culturas indígenas andinas de América del Sur y es acogido por el Ecuador como buen vivir. El sumak kawsay plantea una cosmovisión de armonía de las comunidades humanas con la naturaleza, en la que el ser humano es parte de una comunidad de personas que, a su vez, es un elemento constituyente de la misma Pachamama o Madre Tierra. El sumak kawsay representa una alternativa por cuanto replantea las relaciones entre los seres humanos y la naturaleza, y nos propone un nuevo horizonte de vida y una alternativa frente a la noción monocultural de la actual civilización occidental. Los pueblos indígenas entienden la naturaleza, con una perspectiva holística, como un ente vivo que lo engloba todo, incluidos los seres 
humanos. La naturaleza es la vida y la vida está en todos los elementos de la naturaleza.

El sumak kawsay de los kichwas que habitan el Ecuador implica una estrecha relación con la tierra, con las chacras donde florece la vida y el alimento, con el cuidado y la crianza de los animales, con la fiesta en el trabajo colectivo, en la minga. Está asociado a la vida en comunidad; la vida dulce o vida bonita de los pueblos andinos nos propone un mundo austero y diverso, en equilibrio con la naturaleza y con el mundo espiritual. Representa una alternativa porque replantea las relaciones entre los seres humanos y la naturaleza, nos pone ante la encrucijada de establecer un nuevo contrato social que recupere unas relaciones éticas entre los seres humanos. El vivir bien nos plantea un nuevo horizonte de vida, que no puede asumirse desde una noción monocultural. Esto entraña rupturas importantes, porque nos propone la necesidad de provocar profundas transformaciones en las relaciones sociales, pero también en las relaciones con la naturaleza. El buen vivir o vivir bonito podría contribuir a la articulación de las alternativas que se construyen desde las experiencias de mujeres, indígenas, negros, campesinos y ambientalistas, pero también desde las que se construyen en los movimientos urbanos y de jóvenes, desde los trabajadores y desde los movimientos por la diversidad, de manera que se pueda superar la fragmentación y la sectorización de las propuestas ${ }^{21}$.

En el caso del Ecuador, el buen vivir forma parte de una larga búsqueda de alternativas de vida fraguadas al calor de las luchas populares, particularmente indígenas, desde mucho antes que Rafael Correa asumiera la Presidencia. Sus contenidos apuntan a transformaciones de fondo en la sociedad, la economía, la política y la relación con la naturaleza. Se articularon con agendas de otros movimientos en un conglomerado heterogéneo con fuerzas sobre todo urbanas, hasta cristalizarse en el proceso constituyente del 2008. Esta idea es presentada como los "derechos del

21 Véase Salvador Schavelzon. Plurinacionalidad y VIVIR BIEN/BUEN VIVIR. Dos CONCEPTOS Leídos DESDE Bolivia Y ECUADOR POST-CONSTITUYENTES. Editorial Abya-Yala. (2015); Luis Macas. El Sumak Kawsay. Debates sobre Cooperación y modelos de desarrollo. Perspectivas desde la sociedad CiVil EN el ECuAdor. Editorial Ciudad. (2011). Págs. 47-60; Mario Melo. Los derechos de la naturaleza en la nueva Constitución ecuatoriana. Eds. Alberto Acosta y Esperanza Martínez. Derechos de la Naturaleza. El futuro es ahora. Editorial Abya-Yala. (2009). Págs. 53-59; Fernando Vega. El buen vivir, sumak kawsay en la Constitución y en el PNBV 2013-2017 del Ecuador. REVISTA DE Ciencias Sociales obets 1. 2014. buen vivir", entre los cuales se incluye una amplia variedad de derechos (como a la alimentación, a un ambiente sano, al agua, a la comunicación, a la educación, a la vivienda, a la salud, a la energía, etc.)

A partir de la lectura de las disposiciones regulatorias de estas Constituciones, se puede decir que los textos del Ecuador y de Bolivia aparecen como los abanderados de una nueva figura denominada ecoconstitucionalismo. En el Ecuador, ya se citaba que los derechos de la naturaleza recogidos en la Constitución del 2008 son una novedad jurídica dentro de la cosmovisión indígena del buen vivir. Siendo la Constitución la ley jerárquica de más alto rango jurídico, sus disposiciones son de cumplimiento obligatorio y de acción inmediata en la parte que corresponde al "nuevo constitucionalismo latinoamericano". Ecuador, con esta Constitución, por su novedad y singular tratamiento al aspecto ambiental, ha pasado a ser uno de los países que han asumido este reto.

Lo anterior permite ponderar que, en el plano jurídico, los derechos de la naturaleza fueron aprobados en la Asamblea Constituyente y ratificados por la mayoría del pueblo ecuatoriano, mediante el mecanismo de la consulta popular ${ }^{22}$. Estos derechos fueron reconocidos, regulados y desarrollados de la siguiente manera:

- El artículo 1 señala: "Los recursos naturales no renovables del territorio del Estado pertenecen a su patrimonio inalienable, irrenunciable e imprescriptible".

- El artículo 3 refiere: "Son deberes primordiales del Estado: 7. Proteger el patrimonio natural y cultural del país".

- El artículo 10 señala: "Las personas, comunidades, pueblos, nacionalidades y colectivos son titulares y gozarán de los derechos garantizados en la Constitución y en los instrumentos internacionales. La naturaleza será sujeto de aquellos derechos que le reconozca la Constitución".

22 Véase Constitución de la República del Ecuador de 2008 supra, nota 11; Eugenio Raúl Zaffaroni. La Pachamama Y EL humano. Editorial Madres de la Plaza de Mayo. (2011). Pág. 76; Carlos Villavella Armengol. El derecho constitucional del siglo XXI en Latinoamérica: un cambio de paradigma. Eds. Roberto Viciano Pastor y Rubén Martínez Dalmau. Editores. Estudios SOBRE EL NUEVO CONSTITUCIONALISMO LATINOAMERICANO. Editorial Tirant lo Blanch. (2012). Págs. 51-76. 
Por consiguiente, es un hecho quela Constitución del 2008 rompe con la concepción clásica de priorizar unos derechos sobre otros al reconocerlos como interdependientes y de igual jerarquía, elementos que pueden ser constatados en su desarrollo (artículo 11, numeral 6). Por eso, los derechos al buen vivir ocupan un mismo plano que otros conjuntos de derechos, entre los cuales están los derechos de personas y grupos de atención prioritaria, comunidades, pueblos y nacionalidades, participación, libertad, naturaleza y protección; y a su vez, este conjunto tiene un correlato en una sección dedicada a las responsabilidades.

El artículo 14 señala que "reconoce el derecho de la población a vivir en un ambiente sano y ecológicamente equilibrado, que garantice la sostenibilidad y el buen vivir, sumak kawsay". Y el artículo 15 indica:

El Estado promoverá, en el sector público y privado, el uso de tecnologías ambientalmente limpias y de energías alternativas no contaminantes y de bajo impacto. La soberanía energética no se alcanzará en detrimento de la soberanía alimentaria, ni afectará el derecho al agua. Se prohíbe el desarrollo, producción, tenencia, comercialización, importación, transporte, almacenamiento y uso de armas químicas, biológicas y nucleares, de contaminantes orgánicos persistentes altamente tóxicos, agroquímicos internacionalmente prohibidos, y las tecnologías y agentes biológicos experimentales nocivos y organismos genéticamente modificados perjudiciales para la salud humana o que atenten contra la soberanía alimentaria o los ecosistemas, así como la introducción de residuos nucleares y desechos tóxicos al territorio nacional.

Por otro lado, en el artículo 27 se dispone que:

La educación se centrará en el ser humano y garantizará su desarrollo holístico, en el marco del respeto a los derechos humanos, al medio ambiente sustentable y a la democracia; será participativa, obligatoria, intercultural, democrática, incluyente y diversa, de calidad y calidez; impulsará la equidad de género, la justicia, la solidaridad y la paz; estimulará el sentido crítico, el arte y la cultura física, la iniciativa 28 individual y comunitaria, y el desarrollo de competencias y capacidades para crear y trabajar. La educación es indispensable para el conocimiento, el ejercicio de los derechos y la construcción de un país soberano, y constituye un eje estratégico para el desarrollo nacional.
Elartículo 57 reconoce ygarantiza a las comunas, comunidades, pueblos y nacionalidades indígenas, en conformidad con la Constitución y con los pactos, convenios, declaraciones y demás instrumentos internacionales de derechos humanos, los siguientes derechos colectivos:

5. Mantener la posesión de las tierras y territorios ancestrales y obtener su adjudicación gratuita.

6. Participar en el uso, usufructo, administración y conservación de los recursos naturales renovables que se hallen en sus tierras.

7. La consulta previa, libre e informada, dentro de un plazo razonable, sobre planes y programas de prospección, explotación y comercialización de recursos no renovables que se encuentren en sus tierras y que puedan afectarles ambiental o culturalmente; participar en los beneficios que esos proyectos reporten y recibir indemnizaciones por los perjuicios sociales, culturales y ambientales que les causen. La consulta que deban realizar las autoridades competentes será obligatoria y oportuna. Si no se obtuviese el consentimiento de la comunidad consultada, se procederá conforme a la Constitución y la ley.

8. Conservar y promover sus prácticas de manejo de la biodiversidad y de su entorno natural. El Estado establecerá y ejecutará programas, con la participación de la comunidad, para asegurar la conservación y utilización sustentable de la biodiversidad.

12. Mantener, proteger y desarrollar los conocimientos colectivos; sus ciencias, tecnologías y saberes ancestrales; los recursos genéticos que contienen la diversidad biológica y la agrobiodiversidad; sus medicinas y prácticas de medicina tradicional, con inclusión del derecho a recuperar, promover y proteger los lugares rituales y sagrados, así como plantas, animales, minerales y ecosistemas dentro de sus territorios; y el conocimiento de los recursos y propiedades de la fauna y la flora. Se prohíbe toda forma de apropiación sobre sus conocimientos, innovaciones y prácticas.

En el artículo 66, se reconoce y se garantizará a las personas:

26. El derecho a la propiedad en todas sus formas, con función y responsabilidad social y ambiental. El derecho al acceso a la propiedad se hará efectivo con la adopción de políticas públicas, entre otras medidas. 
27. EI derecho a vivir en un ambiente sano, ecológicamente equilibrado, libre de contaminación y en armonía con la Naturaleza.

Este reconocimiento expreso y tácito se reguló en el artículo 71 y dispone que: "La naturaleza tiene derecho a que se respete integralmente su existencia y el mantenimiento y regeneración de sus ciclos vitales, estructura, funciones y procesos evolutivos. Además, toda persona, comunidad, pueblo o nacionalidad podrá exigir a la autoridad pública el cumplimiento de los derechos de la naturaleza". Una segunda parte de este artículo establece que "el Estado incentivará a las personas naturales y jurídicas, y a los colectivos, para que protejan la naturaleza, y promoverá el respeto a todos los elementos que forman un ecosistema".

El artículo 72 refiere que:

La naturaleza tiene derecho a la restauración y esta restauración será independiente de la obligación que tienen el Estado y las personas naturales o jurídicas de indemnizar a los individuos y colectivos que dependan de los sistemas naturales afectados. En los casos de impacto ambiental grave o permanente, incluidos los ocasionados por la explotación de los recursos naturales no renovables, el Estado establecerá los mecanismos más eficaces para alcanzar la restauración, y adoptará las medidas adecuadas para eliminar o mitigar las consecuencias ambientales nocivas.

El artículo 73 dice: "El Estado aplicará medidas de precaución y restricción para las actividades que puedan conducir a la extinción de especies, la destrucción de ecosistemas o la alteración permanente de los ciclos naturales". Dice además que "se prohíbe la introducción de organismos y material orgánico e inorgánico que puedan alterar de manera definitiva el patrimonio genético nacional".

El artículo 74 determina que: "Las personas, comunidades, pueblos y nacionalidades tendrán derecho a beneficiarse del ambiente y de las riquezas naturales que les permitan el buen vivir". Dice también que "los servicios ambientales no serán susceptibles de apropiación; su producción, prestación, uso y aprovechamiento serán regulados por el Estado".

En el artículo 83, se señala: "Son deberes y responsabilidades de las ecuatorianas y los ecuatorianos, sin perjuicio de otros previstos en la Constitución y la ley: [...] 6. Respetar los derechos de la naturaleza, preservar un ambiente sano y utilizar los recursos naturales de modo racional, sustentable y sostenible".
El artículo 261 dispone que:

El Estado central tendrá competencias exclusivas sobre:

7. Las áreas naturales protegidas y los recursos naturales.

8. El manejo de desastres naturales.

11. Los recursos energéticos; minerales, hidrocarburos, hídricos, biodiversidad y recursos forestales.

Dentro del artículo 267, se establece que:

Los gobiernos parroquiales rurales ejercerán las siguientes competencias exclusivas, sin perjuicio de las adicionales que determine la ley:

4. Incentivar el desarrollo de actividades productivas comunitarias, la preservación de la biodiversidad y la protección del ambiente.

Y en el artículo 274 se establece que:

Los gobiernos autónomos descentralizados en cuyo territorio se exploten o industrialicen recursos naturales no renovables tendrán derecho a participar de las rentas que perciba el Estado por esta actividad, de acuerdo con la ley. Pero, lograr alcanzar el buen vivir requerirá que las personas, comunidades, pueblos y nacionalidades gocen efectivamente de sus derechos, y ejerzan responsabilidades en el marco de la interculturalidad, del respeto a sus diversidades, y de la convivencia armónica con la naturaleza (artículo 275).

Los derechos están íntimamente vinculados a las estrategias de desarrollo, y estas deben atender una planificación participativa en áreas como el trabajo y en las soberanías alimentaria, económica y energética.

En paralelo, el régimen del buen vivir incluye las cuestiones de inclusión y equidad (por ejemplo, educación, salud, vivienda, cultura, etc.), así como la biodiversidad y los recursos naturales. El buen vivir es un concepto todavía en construcción, aunque existe un consenso que representa un quiebre de las ideas convencionales del desarrollo. Ese propósito aparece claramente en la Constitución de Montecristi y, en ese sentido, se incluyen diversas vinculaciones con la temática ambiental.

Se indica que el régimen de desarrollo debe servir al buen vivir y, entre sus objetivos, se lee "recuperar y 
conservar la naturaleza y mantener un ambiente sano y sustentable" (artículo 276), y garantizar el acceso de calidad al agua, aire y suelo, y a los beneficios de los recursos naturales. Estos propósitos generan obligaciones tanto para el Estado, como para las personas y las colectividades (artículos 277 y 278). Se le adjudica una importancia relevante a la planificación estatal (artículos 275 y 277), aunque bajo un marco participativo y descentralizado (artículo 279). Componentes de este tipo dejan al buen vivir dentro del campo del desarrollo sostenible.

En el artículo 278, dice: "Para la consecución del buen vivir, a las personas y a las colectividades, y sus diversas formas organizativas, les corresponde: [...] 2. Producir, intercambiar y consumir bienes y servicios con responsabilidad social y ambiental".

El artículo 281 dispone que:

La soberanía alimentaria constituye un objetivo estratégico y una obligación del Estado para garantizar que las personas, comunidades, pueblos y nacionalidades alcancen la autosuficiencia de alimentos sanos y culturalmente apropiados de forma permanente. Para ello, será responsabilidad del Estado:

1. Impulsar la producción, transformación agroalimentaria y pesquera de las pequeñas y medianas unidades de producción, comunitarias y de la economía social y solidaria.

2. Adoptar políticas fiscales, tributarias y arancelarias que protejan al sector agroalimentario y pesquero nacional para evitar la dependencia de importaciones de alimentos.

3. Fortalecer la diversificación y la introducción de tecnologías ecológicas y orgánicas en la producción agropecuaria.

4. Promover políticas redistributivas que permitan el acceso del campesinado a la tierra, al agua y otros recursos productivos.

5. Establecer mecanismos preferenciales de financiamiento para los pequeños y medianos productores y productoras, facilitándoles la adquisición de medios de producción.

6. Promover la preservación y recuperación de la agrobiodiversidad y de los saberes ancestrales vinculados a ella; así como el uso, la conservación e intercambio libre de semillas.

7. Precautelar que los animales destinados a la alimentación humana estén sanos y sean criados en un entorno saludable.
8. Asegurar el desarrollo de la investigación científica y de la innovación tecnológica apropiada para garantizar la soberanía alimentaria.

9. Regular bajo normas de bioseguridad el uso y desarrollo de biotecnología, así como su experimentación, uso y comercialización.

10. Fortalecer el desarrollo de organizaciones y redes de productores y de consumidores, así como el de comercialización y distribución de alimentos que promueva la equidad entre espacios rurales y urbanos.

11. Generar sistemas justos y solidarios de distribución y comercialización de alimentos. Impedir prácticas monopólicas y cualquier tipo de especulación con productos alimenticios.

12. Dotar de alimentos a las poblaciones víctimas de desastres naturales o antrópicos que pongan en riesgo el acceso a la alimentación. Los alimentos recibidos de ayuda internacional no deberán afectar la salud ni el futuro de la producción de alimentos producidos localmente.

13. Prevenir y proteger a la población del consumo de alimentos contaminados o que pongan en riesgo su salud o que la ciencia tenga incertidumbre sobre sus efectos.

14. Adquirir alimentos y materias primas para programas sociales y alimenticios, prioritariamente a redes asociativas de pequeños productores y productoras.

En el artículo 282, se señala lo siguiente:

El Estado normará el uso y acceso a la tierra que deberá cumplir la función social y ambiental. Un fondo nacional de tierra, establecido por ley, regulará el acceso equitativo de campesinos y campesinas a la tierra. Se prohíbe el latifundio y la concentración de la tierra, así como el acaparamiento o privatización del agua y sus fuentes. El Estado regulará el uso y manejo del agua de riego para la producción de alimentos, bajo los principios de equidad, eficiencia y sostenibilidad ambiental.

En el artículo 283, se dispone que: "El sistema económico es social y solidario; reconoce al ser humano como sujeto y fin; propende a una relación dinámica y equilibrada entre sociedad, Estado y mercado, en armonía con la Naturaleza; y tiene por objetivo garantizar la producción y reproducción de las condiciones materiales e inmateriales que posibiliten el buen vivir." 


\section{El artículo 306 establece:}

El Estado promoverá las exportaciones ambientalmente responsables, con preferencia de aquellas que generen mayor empleo y valor agregado, y en particular las exportaciones de los pequeños y medianos productores y del sector artesanal. El Estado propiciará las importaciones necesarias para los objetivos del desarrollo y desincentivará aquellas que afecten negativamente a la producción nacional, a la población y a la naturaleza.

\section{El artículo 313 establece que:}

El Estado se reserva el derecho de administrar, regular, controlar y gestionar los sectores estratégicos, de conformidad con los principios de sostenibilidad ambiental, precaución, prevención y eficiencia. Los sectores estratégicos, de decisión y control exclusivo del Estado, son aquellos que por su trascendencia y magnitud tienen decisiva influencia económica, social, política o ambiental, y deberán orientarse al pleno desarrollo de los derechos y al interés social. Se consideran sectores estratégicos la energía en todas sus formas, las telecomunicaciones, los recursos naturales no renovables, el transporte y la refinación de hidrocarburos, la biodiversidad y el patrimonio genético, el espectro radioeléctrico, el agua, y los demás que determine la ley.

En el artículo 317, se regula que: "Los recursos naturales no renovables pertenecen al patrimonio inalienable e imprescriptible del Estado. En su gestión, el Estado priorizará la responsabilidad intergeneracional, la conservación de la Naturaleza, el cobro de regalías u otras contribuciones no tributarias y de participaciones empresariales; y minimizará los impactos negativos de carácter ambiental, cultural, social y económico.”

El artículo 318 dispone que:

El agua es patrimonio nacional estratégico de uso público, dominio inalienable e imprescriptible del Estado, y constituye un elemento vital para la Naturaleza y para la existencia de los seres humanos. Se prohíbe toda forma de privatización del agua. La gestión del agua será exclusivamente pública o comunitaria. El servicio público de saneamiento, el abastecimiento de agua potable y el riego serán prestados únicamente por personas jurídicas estatales o comunitarias. El Estado fortalecerá la gestión y el funcionamiento de las iniciativas comunitarias en torno a la gestión del agua y la prestación de los servicios públicos, mediante el incentivo de alianzas entre lo público y comunitario para la prestación de servicios. El Estado, a través de la autoridad única del agua, será el responsable directo de la planificación y gestión de los recursos hídricos que se destinarán a consumo humano, riego que garantice la soberanía alimentaria, caudal ecológico y actividades productivas, en este orden de prelación. Se requerirá autorización del Estado para el aprovechamiento del agua con fines productivos por parte de los sectores público, privado y de la economía popular y solidaria, de acuerdo con la ley.

\section{En el artículo 319, se menciona que:}

[...] se reconocen diversas formas de organización de la producción en la economía, entre otras las comunitarias, cooperativas, empresariales públicas o privadas, asociativas, familiares, domésticas, autónomas y mixtas. El Estado promoverá las formas de producción que aseguren el buen vivir de la población y desincentivará aquellas que atenten contra sus derechos o los de la naturaleza; alentará la producción que satisfaga la demanda interna y garantice una activa participación del Ecuador en el contexto internacional.

El artículo 376 señala que para hacer efectivo el derecho a la vivienda, al hábitat y a la conservación del ambiente, las municipalidades podrán expropiar, reservar y controlar áreas para el desarrollo futuro, de acuerdo con la ley. Se prohíbe la obtención de beneficios a partir de prácticas especulativas sobre el uso del suelo, en particular por el cambio de uso, de rústico a urbano o de público a privado.

El artículo 385 dice que:

[...] el sistema nacional de ciencia, tecnología, innovación y saberes ancestrales, en el marco del respeto al ambiente, la Naturaleza, la vida, las culturas y la soberanía, tendrá como finalidad:

1. Generar, adaptar y difundir conocimientos científicos y tecnológicos.

2. Recuperar, fortalecer y potenciar los saberes ancestrales.

3. Desarrollar tecnologías e innovaciones que impulsen la producción nacional, eleven la eficiencia y productividad, mejoren la calidad de vida y contribuyan a la realización del buen vivir. 
Según el artículo 387, será responsabilidad del Estado: “[...] 4. Garantizar la libertad de creación e investigación en el marco del respeto a la ética, la naturaleza, el ambiente, y el rescate de los conocimientos ancestrales".

Por otro lado, en el artículo 389, el Estado "protegerá a las personas, las colectividades y la naturaleza frente a los efectos negativos de los desastres de origen natural o antrópico mediante la prevención ante el riesgo, la mitigación de desastres, la recuperación y mejoramiento de las condiciones sociales, económicas y ambientales, con el objetivo de minimizar la condición de vulnerabilidad".

Otra de las novedades que se aprecian está vinculada con la responsabilidad objetiva y se percibe en el artículo 396:

[...] el Estado adoptará las políticas y medidas oportunas que eviten los impactos ambientales negativos, cuando exista certidumbre de daño. En caso de duda sobre el impacto ambiental de alguna acción u omisión, aunque no exista evidencia científica del daño, el Estado adoptará medidas protectoras eficaces y oportunas. La responsabilidad por daños ambientales es objetiva. Todo daño al ambiente, además de las sanciones correspondientes, implicará también la obligación de restaurar integralmente los ecosistemas e indemnizar a las personas y comunidades afectadas. Cada uno de los actores de los procesos de producción, distribución, comercialización y uso de bienes o servicios asumirá la responsabilidad directa de prevenir cualquier impacto ambiental, de mitigar y reparar los daños que ha causado, y de mantener un sistema de control ambiental permanente. Las acciones legales para perseguir y sancionar por daños ambientales serán imprescriptibles.

En el artículo 391, se dispone que "el Estado generará y aplicará políticas demográficas que contribuyan a un desarrollo territorial e intergeneracional equilibrado y garanticen la protección del ambiente y la seguridad de la población, en el marco del respeto a la autodeterminación de las personas y a la diversidad".

En el artículo 395, la Constitución reconoce los siguientes principios ambientales:

1. El Estado garantizará un modelo sustentable de desarrollo, ambientalmente equilibrado y respetuoso de la diversidad cultural, que conserve la biodiversidad y la capacidad de regeneración natural de los ecosis- temas, y asegure la satisfacción de las necesidades de las generaciones presentes y futuras.

2. Las políticas de gestión ambiental se aplicarán de manera transversal y serán de obligatorio cumplimiento por parte del Estado en todos sus niveles y por todas las personas naturales o jurídicas en el territorio nacional.

3. El Estado garantizará la participación activa y permanente de las personas, comunidades, pueblos y nacionalidades afectadas, en la planificación, ejecución y control de toda actividad que genere impactos ambientales.

4. En caso de duda sobre el alcance de las disposiciones legales en materia ambiental, estas se aplicarán en el sentido más favorable a la protección de la $\mathrm{Na}$ turaleza.

Ya en el artículo 396, se establece que:

[...] el Estado adoptará las políticas y medidas oportunas que eviten los impactos ambientales negativos, cuando exista certidumbre de daño. En caso de duda sobre el impacto ambiental de alguna acción u omisión, aunque no exista evidencia científica del daño, el Estado adoptará medidas protectoras eficaces y oportunas. La responsabilidad por daños ambientales es objetiva. Todo daño al ambiente, además de las sanciones correspondientes, implicará también la obligación de restaurar integralmente los ecosistemas e indemnizar a las personas y comunidades afectadas. Cada uno de los actores de los procesos de producción, distribución, comercialización y uso de bienes o servicios asumirá la responsabilidad directa de prevenir cualquier impacto ambiental, de mitigar y reparar los daños que ha causado, y de mantener un sistema de control ambiental permanente. Las acciones legales para perseguir y sancionar por daños ambientales serán imprescriptibles.

El artículo 397 regula que:

[...] en caso de daños ambientales, el Estado actuará de manera inmediata y subsidiaria para garantizar la salud y la restauración de los ecosistemas. Además de la sanción correspondiente, el Estado repetirá contra el operador de la actividad que produjera el daño las obligaciones que conlleve la reparación integral, en las condiciones y con los procedimientos que la ley establezca. La responsabilidad también recaerá sobre las servidoras o servidores responsables de realizar el 
control ambiental. Para garantizar el derecho individual y colectivo a vivir en un ambiente sano y ecológicamente equilibrado, el Estado se compromete a:

1. Permitir a cualquier persona natural o jurídica, colectividad o grupo humano, ejercer las acciones legales y acudir a los órganos judiciales y administrativos, sin perjuicio de su interés directo, para obtener de ellos la tutela efectiva en materia ambiental, incluyendo la posibilidad de solicitar medidas cautelares que permitan cesar la amenaza o el daño ambiental materia de litigio. La carga de la prueba sobre la inexistencia de daño potencial o real recaerá sobre el gestor de la actividad o el demandado.

2. Establecer mecanismos efectivos de prevención y control de la contaminación ambiental, de recuperación de espacios naturales degradados y de manejo sustentable de los recursos naturales.

3. Regular la producción, importación, distribución, uso y disposición final de materiales tóxicos y peligrosos para las personas o el ambiente.

4. Asegurar la intangibilidad de las áreas naturales protegidas, de tal forma que se garantice la conservación de la biodiversidad y el mantenimiento de las funciones ecológicas de los ecosistemas. El manejo y administración de las áreas naturales protegidas estará a cargo del Estado.

5. Establecer un sistema nacional de prevención, gestión de riesgos y desastres naturales, basado en los principios de inmediatez, eficiencia, precaución, responsabilidad y solidaridad.

Lo anterior también guarda relación con lo que se dispone en cuanto a la gestión del riesgo, regulada en el artículo 389: “[...] el Estado protegerá a las personas, las colectividades y la naturaleza frente a los efectos negativos de los desastres de origen natural o antrópico mediante la prevención ante el riesgo, la mitigación de desastres, la recuperación y mejoramiento de las condiciones sociales, económicas y ambientales, con el objetivo de minimizar la condición de vulnerabilidad".

En el artículo 398, se establece que:

[...] toda decisión o autorización estatal que pueda afectar al ambiente deberá ser consultada a la comunidad, a la cual se informará amplia y oportunamente. El sujeto consultante será el Estado. La ley regulará la consulta previa, la participación ciudadana, los plazos, el sujeto consultado y los criterios de valoración y de objeción sobre la actividad sometida a consulta.
El Estado valorará la opinión de la comunidad según los criterios establecidos en la ley y los instrumentos internacionales de derechos humanos. Si del referido proceso de consulta resulta una oposición mayoritaria de la comunidad respectiva, la decisión de ejecutar o no el proyecto será adoptada por resolución debidamente motivada de la instancia administrativa superior correspondiente de acuerdo con la ley.

El artículo 399 establece que "el ejercicio integral de la tutela estatal sobre el ambiente y la corresponsabilidad de la ciudadanía en su preservación, se articulará a través de un sistema nacional descentralizado de gestión ambiental, que tendrá a su cargo la Defensoría del Ambiente y la Naturaleza”.

En el artículo 400, “el Estado ejercerá la soberanía sobre la biodiversidad, cuya administración y gestión se realizará con responsabilidad intergeneracional. Se declara de interés público la conservación de la biodiversidad y todos sus componentes, en particular la biodiversidad agrícola y silvestre y el patrimonio genético del país”.

El artículo 403 dispone que "el Estado no se comprometerá en convenios o acuerdos de cooperación que incluyan cláusulas que menoscaben la conservación y el manejo sustentable de la biodiversidad, la salud humana y los derechos colectivos y de la Naturaleza”.

El artículo 404 refiere que "el patrimonio natural del Ecuador único e invaluable comprende, entre otras, las formaciones físicas, biológicas y geológicas cuyo valor desde el punto de vista ambiental, científico, cultural o paisajístico exige su protección, conservación, recuperación y promoción. Su gestión se sujetará a los principios y garantías consagrados en la Constitución y se llevará a cabo de acuerdo al ordenamiento territorial y una zonificación ecológica, de acuerdo con la ley".

El artículo 405 señala que:

[...] el sistema nacional de áreas protegidas garantizará la conservación de la biodiversidad y el mantenimiento de las funciones ecológicas. El sistema se integrará por los subsistemas estatal, autónomo descentralizado, comunitario y privado, y su rectoría y regulación será ejercida por el Estado. El Estado asignará los recursos económicos necesarios para la sostenibilidad financiera del sistema, y fomentará la participación de las comunidades, pueblos y nacionalidades que han habitado ancestralmente las áreas protegidas en su administración y gestión. Las per- 
sonas naturales o jurídicas extranjeras no podrán adquirir a ningún título tierras o concesiones en las áreas de seguridad nacional ni en áreas protegidas, de acuerdo con la ley.

En el artículo 406, el Estado "regulará la conservación, manejo y uso sustentable, recuperación, y limitaciones de dominio de los ecosistemas frágiles y amenazados; entre otros, los páramos, humedales, bosques nublados, bosques tropicales secos $\mathrm{y}$ húmedos $\mathrm{y}$ manglares, ecosistemas marinos $\mathrm{y}$ marinos-costeros".

En el artículo 407, “se prohíbe la actividad extractiva de recursos no renovables en las áreas protegidas y en zonas declaradas como intangibles, incluida la explotación forestal. Excepcionalmente dichos recursos se podrán explotar a petición fundamentada de la Presidencia de la República y previa declaratoria de interés nacional por parte de la Asamblea Nacional, que, de estimarlo conveniente, podrá convocar a consulta popular".

El artículo 408 regula que:

[...] son de propiedad inalienable, imprescriptible e inembargable del Estado los recursos naturales no renovables y, en general, los productos del subsuelo, yacimientos minerales y de hidrocarburos, substancias cuya naturaleza sea distinta de la del suelo, incluso los que se encuentren en las áreas cubiertas por las aguas del mar territorial y las zonas marítimas; así como la biodiversidad y su patrimonio genético y el espectro radioeléctrico. Estos bienes solo podrán ser explotados en estricto cumplimiento de los principios ambientales establecidos en la Constitución. El Estado participará en los beneficios del aprovechamiento de estos recursos, en un monto que no será inferior a los de la empresa que los explota. El Estado garantizará que los mecanismos de producción, consumo y uso de los recursos naturales y la energía preserven y recuperen los ciclos naturales y permitan condiciones de vida con dignidad.

En el artículo 409, se regula:

[...] es de interés público y prioridad nacional la conservación del suelo, en especial su capa fértil. Se establecerá un marco normativo para su protección y uso sustentable que prevenga su degradación, en particular la provocada por la contaminación, la desertificación y la erosión. En áreas afectadas por procesos de degradación y desertificación, el Estado desarrollará y estimulará proyectos de forestación, reforestación y revegetación que eviten el monocultivo y utilicen, de manera preferente, especies nativas y adaptadas a la zona.

El artículo 410 establece que "el Estado brindará a los agricultores y a las comunidades rurales apoyo para la conservación y restauración de los suelos, así como para el desarrollo de prácticas agrícolas que los protejan y promuevan la soberanía alimentaria”.

En el artículo 411, se señala que:

[...] el Estado garantizará la conservación, recuperación y manejo integral de los recursos hídricos, cuencas hidrográficas y caudales ecológicos asociados al ciclo hidrológico. Se regulará toda actividad que pueda afectar la calidad y cantidad de agua, y el equilibrio de los ecosistemas, en especial en las fuentes y zonas de recarga de agua. La sustentabilidad de los ecosistemas y el consumo humano serán prioritarios en el uso y aprovechamiento del agua.

En el artículo 412, se regula que "la autoridad a cargo de la gestión del agua será responsable de su planificación, regulación y control. Esta autoridad cooperará y se coordinará con la que tenga a su cargo la gestión ambiental para garantizar el manejo del agua con un enfoque ecosistémico".

El artículo 413 dispone que "el Estado promoverá la eficiencia energética, el desarrollo y uso de prácticas y tecnologías ambientalmente limpias y sanas, así como de energías renovables, diversificadas, de bajo impacto y que no pongan en riesgo la soberanía alimentaria, el equilibrio ecológico de los ecosistemas ni el derecho al agua".

El artículo 414 establece que "el Estado adoptará medidas adecuadas y transversales para la mitigación del cambio climático, mediante la limitación de las emisiones de gases de efecto invernadero, de la deforestación y de la contaminación atmosférica; tomará medidas para la conservación de los bosques y la vegetación, y protegerá a la población en riesgo”.

El artículo 416 dispone que "las relaciones del Ecuador con la comunidad internacional responderán a los intereses del pueblo ecuatoriano, al que le rendirán cuenta sus responsables y ejecutores, y en consecuencia: [...] 13. Impulsa la creación, ratificación y vigencia de instrumentos internacionales para la conservación y regeneración de los ciclos vitales del planeta y la biosfera". 
Todos estos artículos, a raíz del tratamiento de los derechos de la naturaleza reconocidos en la Constitución del 2008, han incidido en los ecuatorianos un cambio de su mentalidad. Hay una mayor preocupación por proteger a los ríos, por el agua que se consume y por no agredir al espacio que les cobija, que no es otra cosa que la naturaleza, la Pachamama, heredada de los saberes de los pueblos originarios en esta nación, patrimonio de la humanidad ${ }^{23}$. Si no, ¿cómo se explica que leyes tan importantes como la Ley de Aguas y la Ley Minera sean aprobadas en la Asamblea Constituyente y se busque el camino de la consulta a las partes involucradas? ¿Cómo se entiende que exista por lo menos la iniciativa de dejar al petróleo en los yacimientos del Yasuní?, o ¿por qué se piensa en regalías del petróleo, diferentes a las que siempre perduraron en nuestro país, favoreciendo solamente a las compañías multinacionales?

Estos interrogantes constatan cómo han tenido un desarrollo en el ordenamiento jurídico ecuatoriano, dándosele protección a la naturaleza desde la década de los setenta y los ochenta desde el texto supremo y con un actor fundamental. Los pueblos indígenas, ya con voz y voto en la Constituyente en el siglo XXI, han sido regulados a través de cuerpos jurídicos como:

- Ley de Aguas, Ley N. ${ }^{\circ}$ 139, Suplemento Registro Oficial N. ${ }^{\circ} 862$ del 28 de enero de 1992.

- Ley N. ${ }^{\circ} 22.428$ de Fomento a la Conservación de los Suelos.

- Ley de Gestión Ambiental, Codificación. Registro Oficial Suplemento N. ${ }^{\circ} 418$ del 10 de septiembre del 2004.

- Ley de Prevención y Control de la Contaminación Ambiental, Codificación 20 Registro Oficial Suplemento N. ${ }^{\circ} 418$ del 10 de septiembre del 2004.

23 Véase Elisa Canqui. El Vivir Bien, una propuesta de los pueblos indígenas a la discusión sobre el desarrollo. Revista DE CIENCIAS Sociales obets 1. 2011. Págs. 19-33; Iván Narváez y María Narváez. DeRecho ambiental en ClaVe NeOconstitucional (ENFoque Político). Editorial Flacso. (2012); Diana Quirola Suárez. SumaK KaWsay. Hacia Un NUEvo paCto SOCIAL EN armonía CON LA NATURALEZA. Editorial Abya-Yala. (2009); Eugenio Raúl Zaffaroni. Naturaleza como persona. Gaia y Pachamama. Nueva Constitución Política del Estado. Conceptos elementales PARA SU DESARROLLO NORMATIVO. Editorial Vicepresidencia del Estado Plurinacional. (2010). Págs. 103-117; Mauricio Fernando Angulo Ayoví. La Naturaleza como sujeto de Derechos MEdiANTE ACCIÓN DE PROTECCIÓN EN EL ECUAdOR. TeORÍA Y PRÁCTICA. Editorial Albazul. (2011). Págs. 14-15.
- Ley Forestal y de Conservación de Áreas Naturales y Vida Silvestre y su reglamento.

- Ley N. ${ }^{\circ} 74$ suplemento viernes, 10 de septiembre del 2004, Registro Oficial N. ${ }^{\circ} 41$, codificación 2004-O17.

- Código Orgánico Integral Penal Ecuatoriano, Ley 99-49, Registro Oficial N. ${ }^{\circ}$ 2, 25 de enero del 2000.

- Texto Unificado de la Legislación Secundaria del Ministerio del Ambiente.

- Decreto N. ${ }^{\circ} 3516$, Edición Especial N. ${ }^{\circ} 2$ del Registro Oficial, 31 de marzo del 2003.

- Decreto Ejecutivo N. ${ }^{\circ} 1802$ publicado en el Registro Oficial N. ${ }^{\circ} 456$ del 7 de junio de 1994, que contenía las Políticas Básicas Ambientales del Ecuador.

- Ley Orgánica de Salud, Decreto Supremo N. ${ }^{\circ} 188$, Registro Oficial N. ${ }^{\circ} 158$, del 8 de febrero de 1971.

- Ley Orgánica de Transporte Terrestre, Tránsito y Seguridad Vial, publicada en el Suplemento del Registro Oficial N. ${ }^{\circ}$ 398, del 7 de agosto del 2008.

- Ley N. ${ }^{\circ}$, Ley para la Transformación Económica del Ecuador, Registro Oficial Suplemento N. ${ }^{\circ} 34$, del 13 de marzo del 2000.

- Ley Orgánica de Participación Ciudadana.

- Ley 0, Registro Oficial Suplemento N. ${ }^{\circ} 175$ del 20 de abril del 2010.

- Ley Orgánica de Régimen Especial de la provincia de Galápagos, Registro Oficial Suplemento N. ${ }^{\circ} 520$ de fecha 11 de junio del 2015.

Dado lo anterior, la protección a la naturaleza en el Derecho Constitucional Ambiental ecuatoriano ocupa un papel protagónico por el Estado y tiene un desarrollo en el Derecho sustantivo a partir del siglo $\mathrm{xx}$. Ahora bien, es un hecho que este desarrollo ha sido continuado después del reconocimiento expreso y tácito de los derechos indígenas en el pluralismo jurídico, y ha tenido un desarrollo dentro de las políticas públicas en esta nación a través de la Estrategia Ambiental para el Desarrollo Sustentable (2000) y de la Política y Estrategia Nacional de Biodiversidad (2002) en el texto constitucional del 2008.

A su vez, se puede apreciar con la contextualización de políticas públicas en la creación de áreas protegidas en los parques nacionales Yasuní, Sumaco y Galápagos, como parte del manejo de paisajes con categorías de Reservas de la Biosfera, y con los proyectos de corredores ecológicos y de manejo de la conservación de ecosistemas comunes, como un aporte internacional a la protección de la naturaleza. 
Esto permite ponderar que, mientras que el buen vivir ecuatoriano descansa sobre una amplia trama de derechos constitucionales, incluyendo los de la naturaleza como novedad, estas decisiones deben ser analizadas con detenimiento por estar presentes en todos los países (incluido Ecuador), pues corresponden a los deseos de profundizar una veta extractivista para poder financiar el Estado y promover el crecimiento económico. Los altos precios de las materias primas desencadenan enormes presiones para expandir emprendimientos mineros, petroleros o los nuevos monocultivos de exportación ${ }^{24}$.

Bajo el neoextractivismo, la nación ecuatoriana traza emprendimientos que se justifican en acciones que servirán para financiar al Estado, destinado a los programas sociales que luchan contra la pobreza con el desarrollo de políticas públicas a través de la revolución ciudadana. Empero, a pesar de esas buenas intenciones, es un estilo de desarrollo insostenible, de alto impacto social y ambiental, y que reproduce continuos conflictos con los ciudadanos, en este caso donde están asentadas las poblaciones indígenas. Ello ha traído conflictos jurídicos que han transcendido en su solución en la Corte Constitucional del Ecuador ${ }^{25}$.

Con la inclusión del sumak kawsay en la Constitución del 2008, gracias entre otros factores a la acción política de la Conaie y el Pachakutik, el movimiento indígena ecuatoriano ha tomado dicho concepto como estandarte de sus reivindicaciones políticas. La defensa del sumak kawsay reúne reivindicaciones tradicionales del indigenismo ecuatoriano, tales como: el Estado plurinacional, la autodeterminación, el uso y puesta en valor de las lenguas indígenas, el cuidado de la Pachamama, el respeto de las tradiciones y costumbres indígenas, y la organización comunitaria de la sociedad.

24 Véase Alberto Acosta. El Buen Vivir en el camino del post-desarrollo. Una lectura desde la Constitución de Montecristi. Policy PAPER 9. 2010; Philipp Altmann. El Sumak Kawsay en el discurso del movimiento indígena ecuatoriano. Revista Indiana 30. 2013. Págs. 283-299; Javier Ávila Larrea. El enfoque del buen vivir como una visión colectiva. Revista de Ciencias Sociales obets 1.2014; Víctor Bretón, David Cortez y Fernando García. En busca del sumak kawsay. Revista de Ciencias Sociales Iconos 48. 2014.

25 Véase Julio Marcelo Prieto Méndez. Derechos de la natuRALEZA. Fundamento, CONTENIDO Y EXIGIBILIDAD JURISDICCIONAL. Editorial v\&M Gráficas. (2013). Consúltese la página web de la Corte Constitucional del Ecuador (http//:www.corteconstitucional.gob.ec) en relación con las sentencias vinculadas al derecho y protección a la tierra, la biodiversidad y los recursos naturales: 173-12-SEP-CC Caso N. ${ }^{\circ}$ 0785-10-EP.
En este sentido, poner al sumak kawsay en el centro del debate político de las políticas públicas ecuatorianas puede considerarse como un logro del indigenismo. El sumak kawsay tiene tres concepciones diferentes en Ecuador. La primera es como variante del socialismo del siglo xxI, en lo que se ha venido a denominar "socialismo del sumak kawsay". La segunda es como una "utopía por construir", con un planteamiento ecléctico a modo de collage posmoderno al que contribuyen indigenistas, campesinos, socialistas, ecologistas, feministas, pacifistas, sindicalistas, teólogos de la liberación, etc. Y la tercera de estas concepciones, la genuina, es la que han difundido los intelectuales indigenistas ecuatorianos ${ }^{26}$.

Se valora que lo que hace la Constitución ecuatoriana, en su carácter de cuerpo jurídico revolucionario, es reconocer la naturaleza como una entidad jurídica y para ello le reconoce derechos. Interpretación jurídica que en las comunidades ancestrales desde su cosmovisión puede no ser de recibo; para ellos sí es evidente que la naturaleza es otro ser viviente del cual ellos forman parte desde los pueblos originarios.

Este es un debate jurídico en torno a la naturaleza como sujeto de derechos y lo que ello implica, o dicho de otra manera, los derechos de la naturaleza a su protección son verdaderos retos para los juristas del siglo Xxi. Estos retos, más allá de las posturas y consideraciones filosóficas, políticas o ideológicas, plantean una serie de factores, su desarrollo, implementación y cumplimiento podrá medir su efectividad en relación con la protección al medio ambiente y a la naturaleza en el desarrollo del Derecho positivo en el Ecuador. Son auténticas rupturas epistemológicas a las cuales se enfrentarán los estudiosos del Derecho ambiental desde la academia, y quienes dentro de la Administración Pública se ocuparán de su control público y de su tutela ambiental ${ }^{27}$.

26 Véase Antonio Luis Hidalgo-Capitán. El Buen Vivir ECUATORIANO EN EL CONTEXTO DE LA ECONOMÍA POLÍTICA DEL DESArrollo. Desafíos de los Estudios del Desarrollo. Actas del i Congreso Internacional de Estudios del Desarrollo. REEDES y Universidad de Cantabria. (2012); Carpio Benalcázar, supra, 2009, nota 12; Boaventura De Sousa Santos. Hablamos del socialismo del Buen Vivir. Revista Camino Socialista 9. 2010; Eduardo Gudynas. Los DERECHOS DE LA NATURALEZA EN SERIO. RESPUESTAS Y APORTES DESDE LA ECOLOGÍA POLÍticA. Editorial Abya-Yala. (2011).

27 Véase Alcides Antúnez Sánchez. La inspección ambiental. La evaluación de impacto ambiental. La autorización ambiental y la auditoría ambiental. Revista De Derecho uned 18. 2016; Alcides Antúnez Sánchez. La gestión ambiental. Incidencia en el comercio. Revista Veredas do Direito Ambiental e Desenvolvimiento SustentAVEL 26. 2016. 
Pero ¿por qué ocurrió? Ecuador es uno de los países con mayor biodiversidad por metro cuadrado, cuenta con alrededor de 2306 especies amenazadas. Esto no solo es un atractivo turístico; es también una de las más grandes responsabilidades tanto para el Estado como para los ciudadanos del país (deber-derecho). La Constitución, reconociendo esa responsabilidad, le otorgó derechos a la naturaleza, lo cual no es suficiente si estos no se cumplen de manera general. En Ecuador no se están aplicando los principios de precaución y prevención de manera adecuada, en razón de que es uno de los países que tiene mayor incidencia de afectaciones a la naturaleza en América del Sur ${ }^{28}$.

Se considera que la Conferencia Mundial de los Pueblos por el Cambio Climático y los Derechos de la Madre Tierra celebrada en el 2010, en Cochabamba, reunió a representantes de los pueblos, los grupos indígenas, campesinos, movimientos sociales, científicos, académicos y delegaciones oficiales de aproximadamente 142 países, donde se dijo: "Hoy, nuestra Madre Tierra está herida y el futuro de la humanidad está en peligro" 29 . En la Conferencia de las Naciones Unidas sobre Desarrollo Sostenible, conocida como la Cumbre de Río+20, en el 2012, se insertó el tema de "Madre Tierra", y se consideró que la región de América Latina es la parte del mundo que alberga la mayor diversidad de especies y de ecosistemas, cuya pérdida comprometería el futuro de nuestro planeta.

Es un hecho jurídico que la propuesta del reconocimiento de la justicia consuetudinaria en relación con la protección de la Madre Tierra es una demanda que pretende gozar de igual jerarquía que la justicia ordinaria en el Derecho positivo y la construcción de un diálogo entre las distintas maneras de practicar la justicia en el Ecuador. En sí, es una propuesta revolucionaria. No debe dejar de significarse el valor jurídico de los instrumentos internacionales de derechos humanos, que reconocen los derechos a colectividades, comenzando por el derecho a la autodeterminación de los pueblos que consta en el Pacto Internacional de Derechos Civiles y Políticos, en el Convenio 169 de la oIt y en la Declaración

28 Véase Unión Internacional para la Conservación de la $\mathrm{Na}$ turaleza (UICN). Lista RoJa DE EsPeCiES AMENAZADAS DE LA UNióN INTERNACIONAL PARA LA CONSERVACIÓN DE LA NATURALEZA (UiCn). Resumen para América del Sur. uicn. (2014).

29 Son admitidas varias definiciones para mejor entendimiento, que son lo mismo o que significan lo mismo, como Madre Tierra, planeta Tierra, Pachamama y Madre Naturaleza. de las Naciones Unidas sobre Pueblos Indígenas, entre otros.

Todos estos elementos hasta aquí abordados permitirán a futuro continuar la profundización sobre el tema que aborda el ensayo, del estudio del objeto, los principios, los contenidos, los alcances y otros aspectos que sean regulados en una futura Ley Marco de la Madre Tierra, más allá de la cosmovisión y aplicación consecuente de los derechos de las naciones y pueblos indígenas originarios y más allá del pluralismo jurídico. Todo con el fin de que contribuya a establecer la visión y los fundamentos del desarrollo integral en armonía y equilibrio con la Madre Tierra para vivir bien, garantizando la continuidad de la capacidad de regeneración de los componentes y sistemas de vida de la Madre Tierra, recuperando y fortaleciendo los saberes locales y conocimientos ancestrales, en el marco de la complementariedad de derechos, obligaciones y deberes; así como los objetivos del desarrollo integral como medio para lograr el vivir bien, las bases para la planificación, la gestión pública y las inversiones, y el marco institucional estratégico que la implemente ${ }^{30}$.

Que el ensayo sirva como motivación para que los juristas continúen el desarrollo de cuerpos jurídicos que aborden los postulados constitucionales, acompañados de la formación ambiental a partir del conocimiento del Derecho indígena, desde la clave constitucional ambiental, pues es un nuevo constructo en desarrollo.

\section{A MANERA DE CONClusiones}

La nación del Ecuador despierta y contagia al mundo de una gran esperanza por el buen vivir y los Derechos de la naturaleza como sujeto. El reto es pasar del pacto social en armonía con la naturaleza a la transformación profunda que significa dar vida

30 Véase Julio Echeverría. EL Estado EN LA NUEVA Constitución. La nueva Constitución del Ecuador, Estado, Derecho E instituciones. Editorial Corporación Nacional. (2009). Pág. 14; Jorge Pazmiño Freire. Prólogo. Desafíos CONSTITUCIONALES, LA CONSTITUCiÓN ECUATORIANA DEL 2008 en perspectiva. Ministerio de Justicia y Derechos Humanos y Tribunal Constitucional del Ecuador. (2008). Pág. 11; Agustín Grijalva Jiménez. Constitucionalismo EN ECUADor. Editorial v\&M Gráficas. (2012). Págs. 30-190; Agustín Grijalva y Julio César Trujillo. El FUndamento CONSTitucional DE LA NUEVA ECONOMÍA. Centro de Estudios y Difusión del Derecho Constitucional CEDEC. (2012). Págs. 35-48. 
al sumak kawsay, con el nuevo régimen de desarrollo social y solidario que sustente y garantice el pleno ejercicio de los derechos con justicia intergeneracional. El buen vivir, como se anota a lo largo de estas líneas, es un concepto en construcción.

En América Latina, en la década de los setenta se comienza a dar una mirada proteccionista desde los textos constitucionales a la Pachamama. De los veinte países que componen la región, dieciséis lo han reconocido en su carta política. El desarrollo en los ordenamientos jurídicos se ha expresado en leyes ambientales, en leyes de gestión ambiental y en la creación de tribunales agroambientales.

La Constitución ecuatoriana de 1998 y la Constitución del 2008 aportan importantes avances en la armonización cultural y jurídica de las tensiones entre el eurocentrismo y la cosmovisión indígena. Aunque la autodeclaración constitucional del Ecuador como un Estado plurinacional e intercultural implica conceptos en construcción, determinan la base sobre la cual se debe establecer una nueva convivencia en la diversidad para alcanzar el sumak kawsay. Comulgar con el "socialismo del siglo xxi" y el tema de los derechos ambientales con participación ciudadana es una de las novedades que trae como presentación esta Carta Magna.

El pluralismo jurídico en la Constitución del 2008 conforma el campo jurídico ecuatoriano y está compuesto por la justicia ordinaria y la justicia indígena, y tiene a la justicia constitucional como instancia de cierre del sistema jurídico-político. Tres elementos confluyen en la necesidad de tratar este tema para el Ecuador: el marco de discusión global que viene desde finales del siglo pasado sobre las categorías de protección para la conservación que pueden tener espacios naturales de propiedad u ocupados por pueblos indígenas; el crecimiento de los indígenas como sujetos políticos y el carácter de su inclusión en el Estado ecuatoriano; y la confirmación de que gran parte de los espacios naturales, bajo estatus de protección o sin él, son espacios usados y de propiedad indígena.

La naturaleza deja de ser un objeto para convertirse en sujeto de derechos. La nueva Constitución de Ecuador del 2008 es motivo de mucha atención internacional por cuanto presenta dos innovaciones que impactan no solo a los juristas. Por un lado, se reconocen los derechos de la naturaleza y, por el otro, se defiende la idea de una alternativa al desarrollo como Buen Vivir, y se han creado nuevos derechos hasta ahora desconocidos en el constitucionalismo tradicional. Esta perspectiva jurídica permite encontrar muchas vinculaciones con el principio del desarrollo sostenible, como el megaprincipio del Derecho ambiental.

El sumak kawsay, como forma de vida en armonía con la naturaleza y con otros seres humanos, es un concepto que representa la aspiración de muchos pueblos del Abya Yala. La nación ecuatoriana es un referente a tener en cuenta, al ser un concepto jurídico en construcción, cuyo origen nace en el Derecho consuetudinario de los pueblos originarios en la región andina. El reconocimiento de los derechos ambientales de los pueblos indígenas contribuirá a la adopción de cuerpos jurídicos plurales dentro del pluralismo jurídico.

\section{REFERENCIAS}

Adriana Rodríguez Salazar. Teoría y PRÁCtICA DEL BUeN VIVIR: ORÍGENES, DEBATES CONCEPTUALES Y CONFLICTOS SOCIALES. El CASO DE Ecuador. Tesis doctoral, Universidad del País Vasco, Facultad de Derecho. (2016).

Agustín Grijalva Jiménez. Constitucionalismo en EcuADOR. Editorial V\&M Gráficas. (2012).

Agustín Grijalva y Julio César Trujillo. El fundamento Constitucional de la nUeVa eConomía. Centro de Estudios y Difusión del Derecho Constitucional CEDEC. (2012).

André Jean Arnaud y María José Fariñas Dulce. Sistemas JURÍdicos. ElEMENTOS PARA UN ANÁLISIS SOCIOLÓGICo. Boletín Oficial del Estado. (2006).

André Arnaud. Legal Culture and Everyday Life. Edition Oñati Proceedings. (1989).

Antonio Luis Hidalgo-Capitán. El Buen Vivir ecuatoRIANO EN EL CONTEXTO DE LA ECONOMÍA POLÍTICA del desarrollo. Desafíos de los Estudios deL Desarrollo. Actas del i Congreso InternacioNal de Estudios del Desarrollo. Reedes y Universidad de Cantabria. (2012).

Antonio Luis Hidalgo Capitán, Alejandro Guillén García y Nancy Rosario Déleg Guazha. Editores. Sumak KaWSAY Yuyay. Antología del pensamiento IndigeNISTA ECUATORIANo SObRE SUMAK Kawsay. Editorial Universidad de Huelva. (2014).

Alberto Acosta. El Buen Vivir en el camino del post-desarrollo. Una lectura desde la Constitución de Montecristi. Policy Paper 9. 2010. 
Alcides Antúnez Sánchez. La inspección ambiental. La evaluación de impacto ambiental. La autorización ambiental y la auditoría ambiental. Revista DE Derecho UNED 18. 2016. Págs. 1-40.

Alcides Antúnez Sánchez. La gestión ambiental. Incidencia en el comercio. Revista Veredas do Direito Ambiental e Desenvolvimiento Sustentavel 26. 2016. Págs. 1-30.

Alfredo Di Pietro. La prudente tarea de interpretación en el Derecho Romano. ANUARIO DE FILOsofía JURÍdICA Y SOCIAL 9. 1989.

Boaventura De Sousa Santos. O DISCURSO E O PODER: ENSAIO SOBRE A SOCIOLOGIA DA RETÓRICA JURÍDICA. Fabris. (1988).

Boaventura De Sousa Santos. Hablamos del socialismo del Buen Vivir. Revista Camino Socialista 9. 2010. Págs. 4-7.

Carlos Villavella Armengol. El derecho constitucional del siglo XXI en Latinoamérica: un cambio de paradigma. Eds. Roberto Viciano Pastor y Rubén Martínez Dalmau. Estudios SOBRE EL NUEVo CONSTITUCIONALISMO LATINOAMERICANO. Editorial Tirant lo Blanch. (2012).

Código de Hammurabi. Editorial Tecnos. (2014).

Demetrio Loperena Rota. Los PRINCIPIOS DEL DeRECHO Ambiental. Editorial Civitas. (1998).

Diana Quirola Suárez. Sumak Kawsay. Hacia un nuevo PACTO SOCIAL EN ARMONÍA CON LA NATURALEZA. Editorial Abya-Yala. (2009).

Dionisio Fernández De Gatta Sánchez. Principios del Derecho Ambiental, la responsabilidad social corporativa en materia ambiental. Boletín ECONóMICO ICE 2824 (2004).

Eduardo Gudynas. Los DEREChos DE LA NATURALEZA EN SERIO. RESPUESTAS Y APORTES DESDE LA ECOLOGÍA PoLÍticA. Editorial Abya-Yala. (2011).

Elisa Canqui. El Vivir Bien, una propuesta de los pueblos indígenas a la discusión sobre el desarrollo. REVISTA DE Ciencias Sociales obets 1. 2011. Págs. 19-33.

Enrique Ayala Mora. Resumen DE HISTORIA DEL ECUAdoR. Editorial Corporación Nacional. (2008).

Eugène Ehrlich. La sociologia del diritto. Rivista InternaZionAle di Filosofia del Diritto 2. 1992.

Eugène Ehrlich. La norme juridique est une règle sociale parmi d'autres. Eds. Christophe Grzegorczyk, Françoise Michaut y Michel Troper. LE POSITIVISME JURIDIQUE. Editore LGDJ. (1993).
Eugenio Raúl Zaffaroni. NATuraleza como PERsona. Gaia y Pachamama. Nueva Constitución Política del Estado. Conceptos elementales para SU DESARROLLO NORMATIVO. Editorial Vicepresidencia del Estado Plurinacional. (2010).

Eugenio Raúl Zaffaroni. LA PaChamama y el humano. Editorial Madres de la Plaza de Mayo. (2011).

Fernando Vega. El buen vivir, sumak kawsay en la Constitución y en el PNBV 2013-2017 del Ecuador. RevisTA DE Ciencias Sociales obets 1. 2014

Francisco Cuena Boy. Sistema jurídico y Derecho ROMANO. LA IDEA DE SISTEMA JURÍDICO Y SU PROYECCIÓN EN LA EXPERIENCIA JURÍDICA ROMANA. Universidad de Cantabria. (1998)

Henry Levy-Bruhl. Sociología DEL DERECHO. Editorial Universitaria. (1964).

Iván Narváez y María Narváez. Derecho ambiental en Clave neoconstitucional (ENFOQue político). Editorial Flacso. (2012).

Jacques Vanderlinden. État et la régulation juridique des sociétés globales. Pour une problématique du pluralisme juridique. Sociologie et Sociétés 1. 1986.

Jacques Vanderlinden. DictionNAIRE ENCYClOPÉDIQUE DE THÉORIE ET DE SOCIOLOGIE DU DROIT. LGDJ Y Story-Scientia. (1988).

Javier Ávila Larrea. El enfoque del buen vivir como una visión colectiva. Revista de Ciencias Sociales obets 1. 2014. Págs. 43-72.

Jorge Pazmiño Freire. Prólogo. Desafíos constitucioNALES, LA CONSTitución ECUATORIANA DEL 2008 EN PERSPeCtiva. Ministerio de Justicia y Derechos Humanos y Tribunal Constitucional del Ecuador. (2008).

Jorge Salvador Lara. BREvE HISTORIA CONTEMPORÁNEA DEL EcUADOR. Editorial Fondo de Cultura Económica. (2010).

José Esteve Pardo. Principio de precaución. El derecho ante la incerteza científica. Revista Jurídica de CATAlunya 3. 2003. Págs. 689-700.

José Juste Ruiz. La evolución del Derecho Internacional del Medio Ambiente. Autonomies: Revista Catalana De Dret Públic 15. 1992. Págs. 45-60.

Julio Echeverría. El Estado en la nUeva Constitución. La nueva Constitución del Ecuador: Estado, Derecho E Instituciones. Editorial Corporación Nacional. (2009). 
Julio Marcelo Prieto Méndez. Derechos de La naturaleZA. FUNDAMENTO, CONTENIDO Y EXIGIBILIDAD JURISDICCIONAL. Editorial V\&M Gráficas. (2013).

Mario Melo. Los derechos de la naturaleza en la nueva Constitución ecuatoriana. Eds. Alberto Acosta y Esperanza Martínez. Derechos de la Naturaleza. El futuro ES AHORA. Editorial Abya-Yala. (2009). Págs. 53-59.

Masaji Chiba. Legal Pluralism in Sri Lankan Society. Toward a General Theory of Non-Western Law. JOURNAL OF Legal Pluralisim and Non-Official Law 31. 1989.

Masaji Chiba. Una definizione operativa di cultura giuridica nella prospettiva occidentale e non occidentale. SocioLOGIA DEL DiRitTo 3. 1999.

Mauricio Fernando Angulo Ayoví. La Naturaleza como SUJETO DE DERECHOS MEDIANTE ACCIÓN DE PROTECCIÓN EN EL ECUAdor. TeOrÍA Y PRÁCTICA. Editorial Albazul. (2011).

Miguel Berraondo López. Los DERECHOS MEdiOAMBIENTALES DE LOS PUEBLOS INDÍGENAS: LA SITUACIÓN EN LA REGIÓN AMAZÓNICA. Editorial Abya-Yala. (2000).

Néstor Cafferatta. ConstitucionAlismo E INSTITUCIONALIDAD AMBIENTAL EN LATINOAMÉRICA. LA DEMOCRACIA PARTICIPATIVA EN LAS DECISIONES AMBIENTALES. Editorial Ine-Semarnat. (2004).

Néstor Caferrata. Teoría de los principios del Derecho Ambiental. Revista Abeledo Perrot. 2009.

Leopold Pospisil y John Griffiths. What is Legal Pluralism? Journal of Legal Pluralism 24. 1986. Págs. 1-55.

Luis Macas. El Sumak Kawsay. Debates sobre coopeRaCión Y MOdelos DE DESARRollo. Perspectivas DESDE LA SOCIEDAD CIVIL EN EL ECUADOR. Editorial Ciudad. (2011).

Orlando Rey Santos. El DESARROLLO DEL CONSTITUCIONALISMO AMBIENTAL EN LATINOAMÉRICA. PNUMA-ONU. (2008).

Patricio Carpio Benalcázar. El BUEN VIVIR MÁs ALLÁ DEL DESARROLLO: LA NUEVA PERSPECTIVA CONSTITUCIONAL EN EL ECUAdor. Editorial Abya-Yala. (2009).

Philipp Altmann. El Sumak Kawsay en el discurso del movimiento indígena ecuatoriano. REVISTA INDIANA 30. 2013. Págs. 283-299.

Pompeu Casanovas. Dimensiones del Pluralismo JURÍDICO, en IX Congreso de Antropología FAAE, Universidad Autónoma de Barcelona, Madrid, 2002.

Ramiro Ávila Santamaría. Ecuador. Estado constitucional de derechos y justicia. Constitución del 2008 en el contexto andino. Análisis de la doctrina y el Derecho comparado. Serie Justicia y Sociedad 3. 2008. Págs. 19-38.
Ramiro Ávila Santamaría. El NEOCONSTITUCiONALISMo TRANSFORMADOR: EL ESTADO Y EL DERECHO EN LA Constitución DE 2008. Editorial Abya-Yala. (2011).

Ramiro Ávila Santamaría. Los DERECHOS y SUS GARANTÍAS Editorial CEDEC. (2012).

Ramón Martín Mateo. Tratado de Derecho Ambiental. Editorial Trivium. (1998).

Raúl Brañes Ballesteros. Manual de Derecho Ambiental MEXICANO. Fondo de Cultura Económica. (2000).

Raúl Brañes Ballesteros. Informe del Derecho AmbienTAL EN LATINOAMÉRICA, ANÁLISIS HISTÓRICO-DOCTRINAL y JURÍdico DESDE El DeRECho Ambiental. PNUMA-ONU. (2001).

Raúl De Almeida Amoy. Protección del Derecho deL Medio Ambiente en El Derecho interno e interNACIONAL. Editorial Método. (2012).

Sabino Ventura Silva. Derecho Romano. Editorial Porrúa. (1996)

Santi Romano. L'ordenamento gIURIDICo. Editorial Sansoni. (1951).

Salvador Schavelzon. Plurinacionalidad y VIVIR BIEN/ BUEN VIVIR. DOS CONCEPTOS Leídos DESDE Bolivia Y ECUADOR POST-CONSTITUYENTES. Editorial AbyaYala. (2015)

Silvia Jaquenod De Zsogon. El Derecho Ambiental y sus Principios Rectores. Editorial Dykinson. (1991).

Thomas Kuhn. La estructura DE LAS Revoluciones CiEntífiCas. Trad. Agustín Contín. Fondo de Cultura Económica. (2001).

Unión Internacional para la Conservación de la Naturaleza (UiCN). Lista Roja de Especies Amenazadas de la UNión INTERNACIONAL PARA LA CONSERVACIÓN DE la Naturaleza (UiCn). Resumen para América DEL SUR. UICN. (2014),

Vicente De Oliveira Mazzuoli. El Derecho Internacional del Medio Ambiente en la Convención Americana de Derechos Humanos. Anuario Mexicano de Derecho INTERNACIONAL 13. 2013. Págs. 7-49.

Víctor Bretón, David Cortez y Fernando García. En busca del sumak kawsay. Revista de Ciencias Sociales ICONOS 48. 2014. Págs. 9-24. 